\title{
Levelized cost of electricity for photovoltaic/biogas power plant hybrid system with electrical energy storage degradation costs
}

\author{
Chun Sing Lai ${ }^{\mathrm{a}, \mathrm{b}, \mathrm{c}}$, Youwei Jia ${ }^{\mathrm{b}}$, Zhao Xu ${ }^{\mathrm{b}}$, Loi Lei Lai ${ }^{\mathrm{a},{ }^{*}}$, Xuecong $\mathrm{Li}^{\mathrm{a}}$, Jun Cao ${ }^{\mathrm{c}}$, Malcolm \\ D. McCulloch
}

a Department of Electrical Engineering, School of Automation, Guangdong University of Technology, Guangzhou, China, 510006

${ }^{b}$ Department of Electrical Engineering, The Hong Kong Polytechnic University, Hong Kong SAR, China

${ }^{\mathrm{c}}$ Energy and Power Group, Department of Engineering Science, University of Oxford, 17 Parks Road, Oxford OX1 3PJ, United Kingdom

*corresponding author email: 1.1.1ai@ieee.org

Abstract: Off-grid renewable energy system is a critical infrastructure in providing electrical power for small communities, especially in remote and rural areas where grid connection points are not available. Due to the diurnal and intermittent nature of solar irradiance, the photovoltaic (PV) power plant can introduce generation and load power imbalance issue. Anaerobic digestion biogas power plant (AD) also has a part-load operation constraint that needs to be met. To overcome these issues, electrical energy storage (EES) such as Graphite $/ \mathrm{LiCoO}_{2}$ needs to be employed to provide generation flexibility. The research work provided in this paper is twofold. An optimal operating regime is devised for the PV-AD-EES hybrid system, followed by a study on the levelized cost of electricity (LCOE). Degradation cost per $\mathrm{kWh}$ and degradation cost per cycle for EES are considered. 22 years (1994-2015) of irradiance data for Turkwel Gorge Dam, Kenya $\left(1.90^{\circ} \mathrm{N}, 35.34^{\circ} \mathrm{E}\right)$ and the Kenya national load are used for the study. With the current technology costs and a discount rate at $8 \%$, it is shown that the capital cost for $\mathrm{LiCoO}_{2}$ needs to be reduced to $200 \$ / \mathrm{kWh}$ to be economically competitive with dispatchable source such as AD biogas power plant by considering the EES degradation costs.

Index Terms - Off-grid system, battery capacity degradation, photovoltaic system, $\mathrm{LiCoO}_{2}$ battery

\section{Nomenclature}

$\begin{array}{ll}\triangle S O C & \text { Change in state of charge (\%) } \\ \Delta t & \text { Hour interval } \\ \eta_{E E S} & \text { EES round-trip efficiency (\%) } \\ \eta_{P V} & \text { PV array efficiency (\%) } \\ \sigma & \text { Degradation rate for PV (\%) } \\ \varepsilon & \text { Solar irradiance }\left(\mathrm{Wm}^{-2}\right) \\ a, b \text { and } c & \text { Quadratic fuel cost function constants for biogas generator } \\ \mathrm{AD} & \text { Anaerobic digestion } \\ C_{A D_{F u e l}} & \text { Fuel cost for biogas generator }(\$) \\ C_{A D_{\text {Labour }}} & \text { Labour cost for operating the biogas power plant }(\$ 0.05 / \mathrm{kWh})\end{array}$




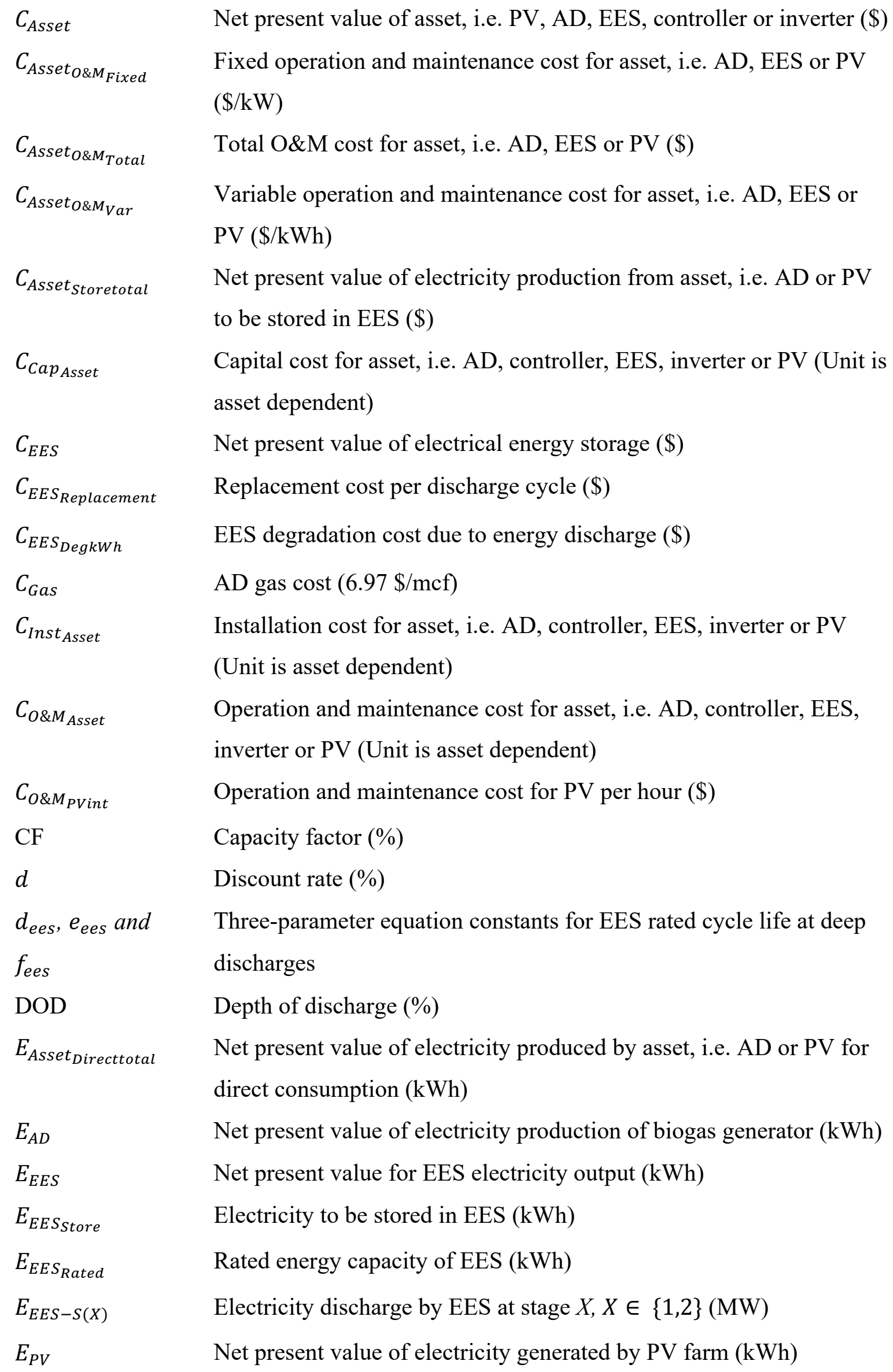




\begin{tabular}{|c|c|}
\hline$E_{\text {Surplus }}$ & Surplus electricity generated by PV system (kWh) \\
\hline EES & Electrical energy storage \\
\hline EMS & Energy management system \\
\hline FiT & Feed-in tariff \\
\hline LCOD & Levelized cost of delivery $(\$ / \mathrm{kWh})$ \\
\hline LCOE & Levelized cost of electricity $(\$ / \mathrm{kWh})$ \\
\hline LCOE $_{\text {Asset }}$ & $\begin{array}{l}\text { Levelized cost of electricity for generation asset, i.e. PV or AD } \\
(\$ / \mathrm{kWh})\end{array}$ \\
\hline $\mathrm{LCOE}_{\text {System }}$ & Levelized cost of electricity for system $(\$ / \mathrm{kWh})$ \\
\hline LCOS & Levelized cost of storage $(\$ / \mathrm{kWh})$ \\
\hline $\mathrm{LiCoO}_{2}$ & Lithium cobalt oxide \\
\hline$L H V$ & Lower heating value (905 btu/ $\left./ \mathrm{ft}^{3}\right)$ \\
\hline$m$ & Number of EES cycles (integer) \\
\hline$n$ & System lifetime (years) \\
\hline$N_{\text {Con }}$ & Number of controllers (integer) \\
\hline$N_{E E S}$ & Number of EES replacements (integer) \\
\hline$N_{\text {Inv }}$ & Number of inverters (integer) \\
\hline$N_{P V}$ & Total number of PV panels (integer) \\
\hline$N_{\text {Store }}$ & Number of PV panels for generating electricity for storage (integer) \\
\hline$N D C$ & Normalised discharge capacity $(\%)$ \\
\hline $\mathrm{NaS}$ & Sodium-sulphur \\
\hline $\mathrm{NiMH}$ & Nickel-metal hydride \\
\hline O\&M & Operation and maintenance \\
\hline$P_{A D}$ & Output power of biogas power plant (MW) \\
\hline$P_{A D_{\text {Max }}}$ & Rated power capacity of biogas power plant (MW) \\
\hline$P_{A D_{\text {Min }}}$ & Minimum output power of biogas power plant (MW) \\
\hline$P_{\text {Asset }}$ Direct & $\begin{array}{l}\text { Power generated with asset, i.e. AD or PV for direct consumption } \\
\text { (MW) }\end{array}$ \\
\hline$P_{\text {Asset }}$ Store & Power generated with asset, i.e. AD or PV for storage (MW) \\
\hline$P_{\text {Con }}$ & Rated power of controller $(\mathrm{kW})$ \\
\hline$P_{E E S_{S(X)}}$ & EES power discharge at stage $X, X \in\{1,2\}$ (MW) \\
\hline$P_{\text {Generation }}$ & Power generation (MW) \\
\hline
\end{tabular}




$\begin{array}{ll}P_{\text {Load }} & \text { Power demand (MW) } \\ P_{I n v} & \text { Rated power of inverter (kW) } \\ P_{P V} & \text { Output power of PV plant (kW) } \\ P_{P V_{\text {Rated }}} & \text { Rated capacity of PV plant (kW) } \\ P_{\text {Surplus }} & \text { Surplus power generated by PV farm (MW) } \\ \text { PV } & \text { Photovoltaic } \\ \text { Ratedcycle } & \text { Rated cycle life of EES (integer) } \\ \text { SOC } & \text { State of charge (\%) } \\ S O C_{\text {Lower }} & \text { The minimum SOC value of a cycle (\%) } \\ S O C_{\text {Max }} & \text { Maximum state of charge (\%) } \\ S O C_{\text {Mean }} & \text { Mean state of charge (\%) } \\ S O C_{\text {Min }} & \text { Minimum state of charge (\%) } \\ S O C_{\text {Threshold }} & \text { SOC threshold (\%) } \\ S O C_{\text {Upper }} & \text { The maximum SOC value of a cycle (\%) } \\ \text { SSR }_{t} & \text { Self-sufficiency Ratio (unitless) } \\ t & \text { Time (hour) }\end{array}$

\section{Introduction}

Electrical energy storage (EES) plays an increasingly important role in electrical power systems, especially for energy balancing in off-grid systems. With the escalation of energy demand and the pressure to reduce environmental pollution, renewable energy source such as solar photovoltaic (PV) needs to be adopted [1,2]. For countries located in Africa at the equator, e.g. Kenya, there is an abundant amount of solar insolation throughout the year. In addition, the waste product generated from the large agricultural industry in Kenya makes electrical power generation from biogas power plant via anaerobic digestion (AD) a desirable option [1]. Hence, the optimal hybrid energy system for a rural community in Kenya should consists of solar PV and AD biogas power plant. In this paper, the term AD represents the combination of the anaerobic digester and the biogas power plant.

In general, off-grid hybrid renewable energy systems perform better with multiple energy sources compared to a single energy source [3]. This can be explained by the fact that different energy sources have different technical constraints, and may be used to complement each other and to maximise the security of supply. The generation costs could also be potentially reduced. However, the control, design, and optimization of such systems is a complicated matter. In general, many of these systems were designed to with the aim to minimize the total generation cost such as the levelized cost of electricity (LCOE) $[3,4]$.

The operation strategy for a system with an EES and PV generator is relatively simple. Surplus energy is stored in EES and discharges if the load is greater than generation. The interesting questions arise for systems with multiple energy sources. For the case where a dispatchable source such as $\mathrm{AD}$ is included, it is required to determine how the EES is charged and which dispatchable source (AD or EES) to use when the load demand is greater than the 
generation. As mentioned in [4], there are three basic control strategies for a PV-Diesel-EES system. These are known as zero-charge strategy, full cycle-charge strategy and the predictive control strategy. The EES is never charged with the diesel generator in the zero-charge strategy. Diesel generator is used to charge the EES to $100 \%$ state of charge (SOC) when the generator is on for the full cycle-charge strategy. Predictive control strategy requires the forecast of renewable generation and load demand to charge the EES. The advantage of this strategy is that energy wastage in surplus energy production from renewables is reduced. An interesting research question to be answered is to determine the optimal point for the $\mathrm{SOC}$, between $0 \%$ to $100 \%$ to be charged with $\mathrm{AD}$ in order to provide a minimum operational cost [4]. In other words, the strategy will be less of an extreme and is between zero-charge and full cycle-charge.

Scheduling regimes such as rule-based strategies [5] have the advantages in avoiding the need of renewable and load forecasting for optimal operation. Additionally, complexity is further reduced when online optimization is not required. The work did not mention the degradation and costs of EES and have highlighted as a future work.

There are numerous amount of research works in cycle life studies and the costs due to EES degradation for hybrid renewable energy systems [6-9]. However, most do not consider partial charge-discharge cycles and uses depth of discharge (DOD), i.e. only accurate for initial SOC at $100 \%$ for EES cycle life calculations. Electrical energy delivered is also used to consider the DOD in some literatures such as [6] and the actual values of the two SOCs may be neglected. Theoretically as an example, the electrical energy output from EES at SOCs of $100 \%$ to $80 \%$ may be the same as a situation for $40 \%$ to $20 \%$. Recent literatures $[10,11]$ have confirmed that partial charge-discharge cycles at different SOC states have a profound effect to the State of Health, i.e. discharge capacity of the EES, and consequently affects the total available cycle life.

Due to irregular load demands and the PV power fluctuations induced from stochastic solar irradiance, the hybrid power system is highly susceptible to irregular SOCs and charge and discharge cycles. It is of paramount importance that the degradation costs and replacement costs are accurately accessed for EES in hybrid power system analysis and optimization. This work aims to provide a study on the economic projection of the hybrid system with the battery degradation costs included by considering the SOCs of each partial discharge cycle. To achieve this, an operating regime is proposed for the hybrid system that provides the optimal dispatch of PV, AD and EES. Having identified the power output and the SOCs for the system with respect to the system lifetime, LCOE is calculated for each asset and for the system. The cost and energy production will be critically analysed.

Section 2 provides a literature review on renewable hybrid system and EES operations. Section 3 presents the data analysis and operating regime for the system. Case studies will be conducted and discussed. The cost analysis for the system will be presented in Section 4. The models for degradation per cycle and degradation per $\mathrm{kWh}$ will be derived. Finally, Section 5 draws the conclusion and future work will be discussed.

\section{Literature review}

In the recent decade, there is an upsurge in research related to using EES for power systems, such as in charging regimes for electric vehicles $[6,7,12]$, profit maximization with energy tariffs $[13,14]$ and off-grid system operations $[2,4]$. Mostly, these literatures have considered the degradation effect of EES to an extent and have made attempts to consider the storage costs. However, the effects of irregular cycling and partial cycles of EES are not properly addressed. Some works have considered to use reference DOD to compute the rated cycle life for the EES.

Reference [15] presents the grid-tied electrical hubs with distributed generation and energy storage for providing the electricity demand in Sri Lanka. The SOC for the EES has been 
considered for the control of the dispatchable energy source. However, the cost of storage and degradation effect have not been included.

The economic operation for a diesel-PV-EES island microgrid in rural areas with a twostage model predictive control strategy is proposed in [16]. The system's economic is assessed with the LCOE metric. Replacement and operational costs for EES are included in the study, which is a function of DOD and cycle life. However, it is unclear how the DOD and cycle life are included and considered.

Levelized cost of delivery (LCOD) is proposed in [17] to compute the levelized cost of EES in PV system. The highlight of the work is that it is necessary to include the electrical energy production costs, i.e. generators cost into the storage costs. The work could be improved by also including the cost aspect of EES degradation.

EES degradation is considered with a fixed degradation cost in [18]. The cost competitiveness of the EES with respect to conventional generation is not provided.

Comparison of different energy storage technologies in a variety of realistic microgrid settings has been developed in [19]. The Energy System Model aims to provide similar functions to the well-known microgrid software HOMER, but with improvements in battery modelling. It is not known if and how the costs in partial cycles and irregular discharges are considered.

The economic feasibility of EES for electric bill management applications has been provided in [20]. A range of EES has been included, these are Li-ion, zinc battery, an advanced lead-acid, a sodium-sulphur (NaS) and a flow battery with no degradation consideration. The techno-economic assessment of distributed EES for load shifting application is provided in [21]. A Li-ion, $\mathrm{NaS}$ and a redox battery were included in the study but again no degradation is considered.

The work in [22] aims to develop degradation cost functions for optimization models in off-grid power system. The battery replacement cost has been provided for different ratios for battery degradation cost to diesel cost. Levelized cost is not calculated for the system.

An exhaustive study in determining the optimal combination of renewable electricity sources and EES connected to a $72 \mathrm{GW}$ grid system is provided in [23]. The aim is to find the least-cost combination of renewable generation and EES to match the load demand. It concluded that excess renewable production can result in lower costs for the system. The argument is that the electrical load will be met with less storage, lowering the total system cost. The LCOE has not been studied and it is unknown how storage degradation costs are considered.

Reference [7] proposes an optimal generation scheduling model for a system with thermal power plant, PV plant, wind farm and EES whilst considering the degradation cost of ESS. Lead-acid and nickel metal hydride $(\mathrm{NiMH})$ batteries were considered. This work aims to include the temperature and DOD for the battery degradation cost. The battery degradation cost is modelled and fitted with a piecewise linear function. However, cycle life effects with irregular cycling were not considered and the degradation model is only applicable for the cycles with initial SOC at $100 \%$.

As reported in [13], a Feed-in tariff(FiT) scheme is already established in Japan to promote the use of PV generators with electric batteries. Also mentioned in [24], FiT schemes could benefit the deployment of EES in the current and upcoming PV systems. This has already happened in other countries such as Germany, where a FiT scheme that maximizes selfconsumption by using EES has been established. There are many researchers studied the operation of grid-connected PV-EES system, however, seldom attention has been paid to the impact of the EES degradation characteristics. The work in [13] aims to evaluate the energy and cost savings for a grid-connected PV-EES system for a household. Operational optimization model was constructed for considering the degradation characteristics of EES. 
The model has two objective functions, known as the operating costs and energy savings. The study concluded that a grid-connected PV-EES system was more useful in energy saving operation. The cycle degradation is defined by the number of cycles and the cycle degradation rate. DOD degradation is considered to have occurred when the DOD is more than $70 \%$.

The stochastic problem for microgrid energy scheduling with distributed generator and controllable loads such as plug-in electric vehicles is presented in [6]. EES degradation costs and cycle life were calculated with DOD. The DOD in this case is the ratio of the energy delivered from the EES to the rated energy capacity. Partial cycling is not included or discussed.

HOMER has been used for the design of a PV-biomass-diesel hybrid systems for off-grid and grid-connected scenarios in [25]. The system's configuration is optimized for different load profiles. Surrtte 6CS25P flooded battery is used for the off-grid case. Details or studies for the EES has not been provided.

Reference [26] proposes a method to simultaneously optimize the rule-based operation strategy and the EES capacity for a grid-connected PV-EES system. Given the present cost of storage, it claimed that using EES with the conventional operation strategy is not profitable but increases the Self-sufficiency Ratio (SSR). It reported that the system uses more renewables with a higher SSR.

A microgrid charging and discharging strategy is given in [8]. A three-parameter function is fitted to estimate the battery cycle life under different DODs. With this function, the depreciation cost model of li-ion battery is developed. The authors acknowledged that the battery charge and discharge cycles under working conditions are composed of several microcycles with different DOD. To overcome this issue, the rain-flow counting method is employed to decompose the complex cycles to micro cycles of different DOD. Charge/discharge cycles are counted with corresponding to each range of the DOD for the year. Partial cycling is not included and this method may not be appropriate if the initial SOC is not at $100 \%$. A sizing methodology with loss of load probability for an off-grid PV system with lead-acid battery is presented in [27]. This work also adopts the rain-flow counting method for battery lifetime estimation. It is unclear if the rain-flow counting method can accurately represent the EES degradation, and a comparison with capacity fade model should be made.

A model for the operation of distribution companies in regulating price or locational marginal price mechanisms is given in [9]. Two types of EES were considered namely leadacid and lithium-ion. It could be observed that there were multiple partial charging and discharging, at different SOCs throughout the time interval. It needs to take into account of the partial cycles for a more accurate optimization problem formulation.

Reference [5] presents the rule-based strategies for operating an EES connected to a selfconsumed PV system to reduce payments to the grid. As stated by the authors, presently the work does not consider the degradation cost of using the EES.

As suggested in the literature review, at present there is little to no work in considering the costs of power system operation for EES energy discharge at different SOC ranges. This research aims to provide a method in incorporating partial cycles at different $\mathrm{SOC}$ ranges for the techno-economic assessment of a PV-AD-EES hybrid system with a proposed operating regime.

\section{Data analysis and operating regime}

\subsection{Solar and load data analysis}

Real-life solar irradiance data were obtained from Solargis for Turkwel Gorge Dam, Kenya with coordinates $1.90^{\circ} \mathrm{N}, 35.34^{\circ} \mathrm{E}$ and elevation at $1170 \mathrm{~m}$. The dataset contains 22 years (19942015) of data with sampling rate at 1 sample/15min. Since the PV output power is influenced 
by the solar irradiance, it is crucial to know how season variations could impact the amount of solar irradiance received by the panels. The monthly solar insolation is computed for the dataset and for comparison purposes, the 22-year monthly solar insolation data from NASA were obtained in [28]. As solar PV is a non-dispatchable source, capacity factor (CF) is used to represent its annual energy output. $\mathrm{CF}$ is the ratio of the actual electrical energy output over the year to the maximum possible electrical energy output over the same time period. The CF is calculated for a $5 \mathrm{MW} \mathrm{PV} \mathrm{farm} \mathrm{with} \mathrm{inclusion} \mathrm{of} \mathrm{solar} \mathrm{panel} \mathrm{efficiency} \mathrm{losses} \mathrm{at} 15 \%$ [1]. Fig. 1 presents the monthly solar insolation and the annual capacity factor for the PV farm.
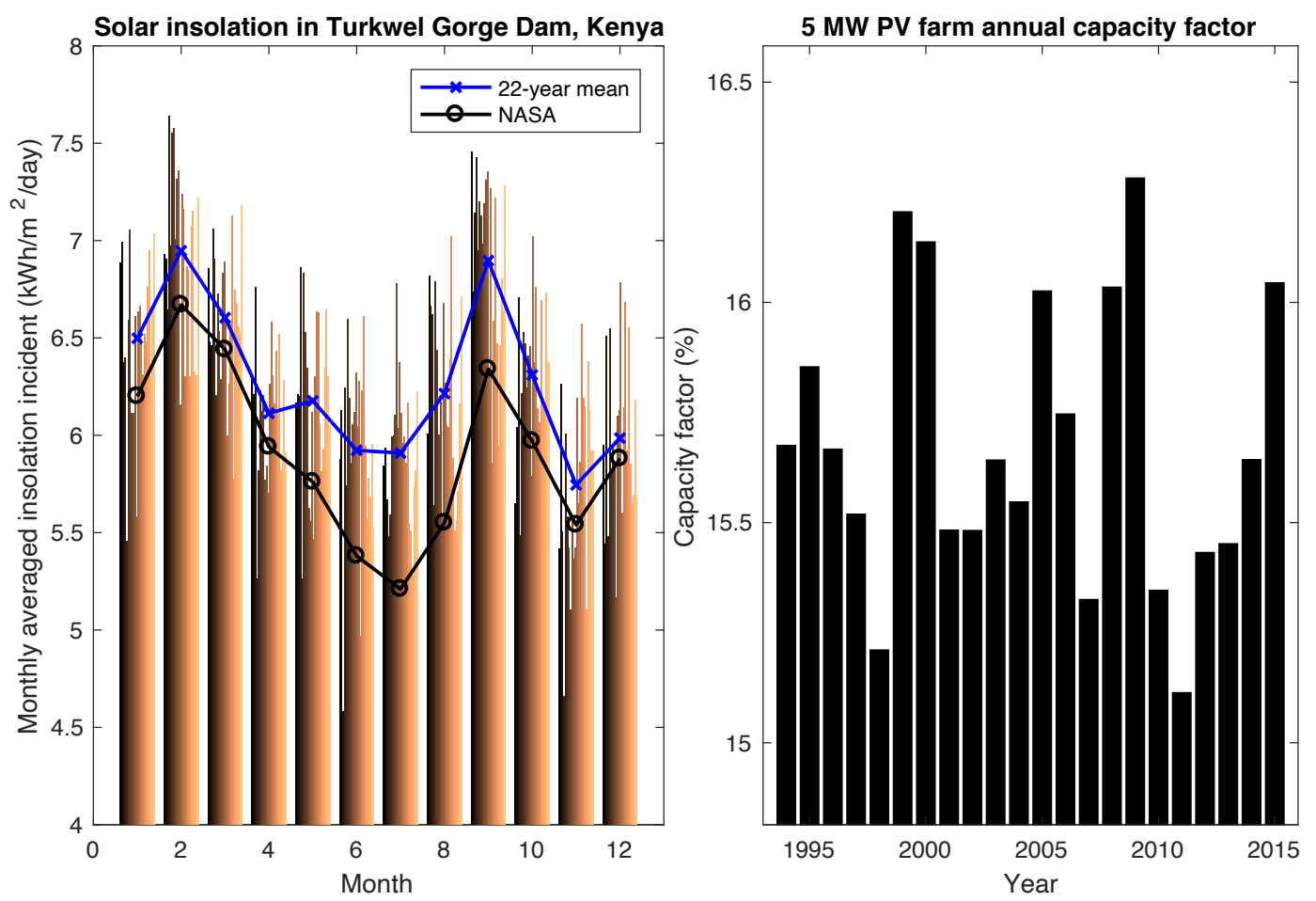

Fig. 1. Solar insolation and capacity factor for solar farm.

As shown in Fig. 1, the differences in annual CF could be significant. The CFs are $15.2 \%$ and $16.3 \%$ for 2011 and 2009 respectively, which is more than $1 \%$ difference. This shows that it may be inaccurate to assume CF to be the same annually throughout the system lifetime. As reported in [29], a method to overcome this issue is to perform sensitivity analysis to CF to calculate the LCOE for hybrid system. However, CF only produces a single value by taking account of the energy generation, hence the information regarding the fluctuations and stochastic information will be missed. This should be taken into account for a more accurate LCOE analysis by using actual generation data per interval. The insolation results in Fig. 1. show a notable trend and is similar to the results from NASA. Least insolation is received during Spring (March to May) and Summer (June to Aug), with the most are received in Autumn (Sept to Oct) and Winter (Dec to Feb), with the exception in November due to repeated rain. 
The Kenya national load data is similar to the studies used in [1, 17]. Table 1 presents the normalized load data for Kenya. The normalized load is multiplied with a $2 \mathrm{MW}$ demand to represent the electrical load demand for a community in a rural area.

\subsection{Problem context}

The aim of the system is to provide the required electrical power, with PV, AD and EES to meet the load demand at all times. This means that the generation and load power should be balanced. The equality constraints for power balance are given in Equations (1) and (2).

$$
\begin{gathered}
P_{\text {Generation }}(t)=P_{\text {Load }}(t) \\
P_{\text {Generation }}(t)=P_{P V_{\text {Direct }}}(t)+P_{A D_{\text {Direct }}}(t)+P_{E E S_{S 1}}(t)+\eta_{E E S} P_{E E S_{S 2}}(t)
\end{gathered}
$$

$P_{P V_{\text {Direct }}}$ and $P_{A D_{\text {Direct }}}$ are the PV and AD power that is used to meet the load directly. $P_{E E S_{S 1}}$ and $P_{E E S_{S 2}}$ are the stage 1 and stage 2 power output from EES. Stage 1 is when the EES decides to output power to meet the demand when the energy stored in EES is above a SOC threshold. Stage 2 is when the EES output power to meet the energy deficit in the system. $\eta_{E E S}$ is the round-trip efficiency for the storage system. This will be further elaborated with introduction of the operating regime in Section 3.3.

The SOC limits are defined in Equation (3) to prevent EES over charging/discharging. The power output of biogas generator should not exceed its rated capacity as shown in Equation (4). Due to the minimum loading constraint for the biogas power plant, it is required to turn off when the power output is below $40 \%$ of its rated power output [1], given in Equation (5).

$$
\begin{gathered}
S O C_{\text {Min }} \leq S O C(t) \leq S O C_{\text {Max }} \\
P_{A D_{\text {Min }}} \leq P_{A D_{\text {Direct }}}(t)+P_{A D_{\text {Store }}}(t) \leq P_{A D_{\text {Max }}} \\
P_{A D_{\text {Min }}}=0.4 * P_{A D_{\text {Max }}}
\end{gathered}
$$

$P_{A D_{\text {Store }}}$ is the power output from AD that is stored in EES. $P_{A D_{\text {Min }}}$ and $P_{A D_{\text {Max }}}$ are the maximum and minimum power output from $A D$ respectively. $S O C_{\text {Min }}$ and $S O C_{\text {Max }}$ are the maximum and minimum SOCs respectively. The instantaneous power output of PV plant is calculated as a function of panel area $N_{P V}$, panel efficiency $\eta_{P V}$ and instantaneous irradiance $\varepsilon(t)$ in Equation (6).

\section{Table 1}

Kenya normalized national load demand [1].

\begin{tabular}{cccc}
\hline \hline Hour & Normalized load & Hour & Normalized load \\
\hline 0 & 0.61 & 12 & 0.81 \\
1 & 0.57 & 13 & 0.80 \\
2 & 0.55 & 14 & 0.78 \\
3 & 0.55 & 15 & 0.79 \\
4 & 0.55 & 16 & 0.81 \\
5 & 0.62 & 17 & 0.81 \\
6 & 0.72 & 18 & 0.81 \\
7 & 0.82 & 19 & 0.86 \\
8 & 0.82 & 20 & 1.00 \\
9 & 0.86 & 21 & 0.96 \\
10 & 0.84 & 22 & 0.86 \\
11 & 0.82 & 23 & 0.71 \\
\hline \hline
\end{tabular}




$$
P_{P V}(t)=\varepsilon(t) \cdot N_{P V} \cdot \eta_{P V}
$$

The schematic for the hybrid system is presented in Fig. 2. It shows that the bi-directional inverter is used to provide DC power to AC load, and is also used for charging the EES from $\mathrm{AD}$. The cost and size of components are given in Table 2 .

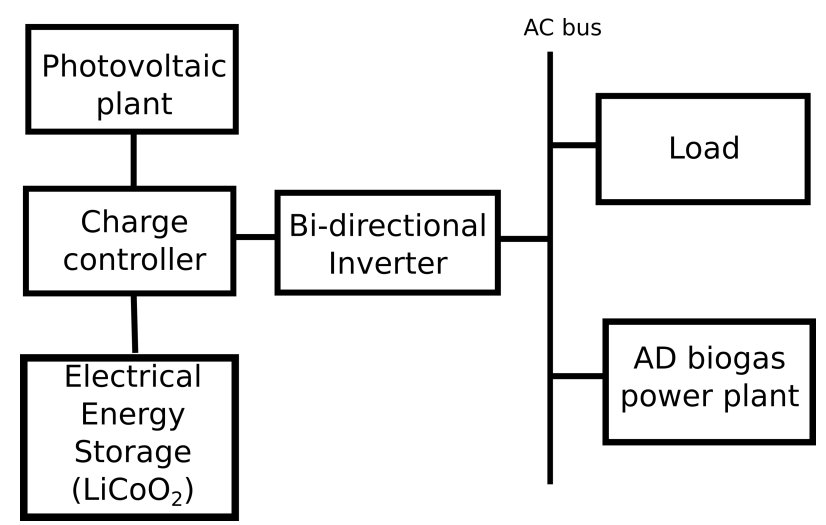

Fig. 2. Schematic diagram of hybrid system.

\section{Table 2}

Cost and components size.

\begin{tabular}{|c|c|c|c|c|c|}
\hline & $\begin{array}{l}\text { PV } \\
\text { (Sharp } \\
\text { ND- } \\
\text { 250QCS) }\end{array}$ & $\begin{array}{l}\text { AD } \\
\text { (Caterpillar } \\
\text { G3512E } \\
\text { Genset) }\end{array}$ & $\begin{array}{l}\text { EES } \\
(\text { Graphite/ } \\
\left.\mathrm{LiCoO}_{2}\right)\end{array}$ & $\begin{array}{l}\text { Controller } \\
\text { (Outback } \\
\text { FM 80) }\end{array}$ & $\begin{array}{l}\text { Inverter } \\
\text { (Schneider } \\
\text { Electric } \\
\text { XW6048) }\end{array}$ \\
\hline Size & $250 \mathrm{~W}$ & $1.2 \mathrm{MW}[30]$ & $2 \mathrm{MW}, 5 \mathrm{MWh}$ & $2 \mathrm{~kW}[1]$ & $6 \mathrm{~kW}[31]$ \\
\hline Unit & $\begin{array}{l}20000 \\
{[1]}\end{array}$ & $2[1]$ & $1[1]$ & 2500 & 834 \\
\hline$C_{\text {Cap }}$ Asset & $\begin{array}{l}120 \\
\text { (\$/unit) } \\
{[1]}\end{array}$ & $\$ 7.5 \mathrm{M}[1]$ & $\begin{array}{l}1500(\$ / \mathrm{kWh}) \\
{[17]}\end{array}$ & $\begin{array}{l}335 \text { (\$/unit) } \\
{[1]}\end{array}$ & $\begin{array}{l}1518 \text { (\$/unit) } \\
\text { [31] }\end{array}$ \\
\hline$C_{\text {Inst }}$ Asset & $\begin{array}{l}108 \\
\text { (\$/unit) } \\
{[1]}\end{array}$ & N/A & N/A & $\begin{array}{l}6.7 \text { (\$/unit) } \\
{[1]}\end{array}$ & $\begin{array}{l}30.38 \\
\text { (\$/unit) [31] }\end{array}$ \\
\hline$C_{\text {Asset }_{\text {O\&M }} \text { Var }}$ & $\mathrm{N} / \mathrm{A}$ & $\begin{array}{l}C_{A D_{\text {Fuel }}} \\
+C_{A D_{\text {Labour }}}\end{array}$ & $\begin{array}{l}0.42(\$ / \mathrm{MWh}) \\
{[17]+} \\
C_{E E S_{\text {DegkWh }}}\end{array}$ & $\mathrm{N} / \mathrm{A}$ & N/A \\
\hline$C_{\text {Asset }}{ }_{\text {O\&M }}$ Fixed & $\begin{array}{l}6 \\
\text { (\$/unit/y } \\
\text { ear) [1] } \\
\end{array}$ & $\begin{array}{l}300(\$ / \mathrm{kW}- \\
\text { year })[32]\end{array}$ & $\begin{array}{l}2.12(\$ / \mathrm{kW}- \\
\text { year) [17] }\end{array}$ & $\begin{array}{l}1.005 \\
\text { (\$/unit/year) } \\
{[1]}\end{array}$ & $\begin{array}{l}4.6 \\
\text { (\$/unit/year) } \\
{[31]}\end{array}$ \\
\hline
\end{tabular}

\subsection{Operating regime}

In the microgrid context, energy management system (EMS) is employed by grid operators to monitor, control, and optimize the performance of the microgrid. The primary aims are to reduce electricity production costs and to continuously fulfil the load requirement. In explicit terms, the definition of energy management given in [33] is the procedure to "collect all the 
systematic procedures to control and minimize the quantity and the cost of energy used to provide a certain application with its requirements." In general, the control architecture of energy management can be classified into two types, namely Centralized control and Decentralized or Distributed control. Hybrid control featuring both centralized and decentralized is also an emerging architecture. As reviewed in $[33,34]$, the choice of the control architecture depends on the scale, configuration and assets ownership of the microgrid.

The work in [35] presents a multi-agent decentralized EMS for autonomous polygeneration microgrids. In a decentralized architecture, each system component features a local controller, as opposed to the centralized architecture where a single controller executes the energy management for the system. Hence, decentralized architecture can increase the system reliability and reduce the chance of a system complete failure. On the other hand, decentralized architecture requires complex communication systems for local controllers to communicate and the achievement of global optimization can be challenging [33].

Traditionally, the optimization strategy employed by EMS for hybrid renewable energy systems are commonly achieved by artificial intelligent techniques or linear programming [33]. Artificial intelligent techniques that have been adopted are particle swarm optimization, genetic algorithm, fuzzy logic and neural network. These techniques have improved the optimization and performance of energy systems over the years. However, real-time and robust energy management techniques are still a major focus in future research, due to the drawbacks in determining the global optimal and the computational costs. This work employs rule-based approach to avoid the drawbacks of artificial intelligence methods and to achieve optimal dispatch.

Microgrids can be categorized into five categories, where each category is designed to meet specific goals. These are namely the commercial/industrial, community/utility, campus/institutional, military and remote [36]. Taking these consideration in mind, this work focuses on developing an EMS for a remote community with generation assets locate closely together, simple data acquisition and inexpensive architecture; a centralized architecture is adopted for this system.

The off-grid system will operate at the most cost-effective manner with the proposed regime. In essence, the operating regime will operate with the following characteristics:

- Since the fuel cost for PV is zero, PV will be given the priority and firstly be used to meet the load demand before the deployment of AD or EES power;

- Surplus PV energy will be stored in EES while fulfilling the SOC constraints;

- $\mathrm{AD}$ will be used to meet the load demand when PV power is not available;

- EES will be used to meet the deficit energy, i.e. the situation when no PV power is available and $\mathrm{AD}$ is switched off.

- During the situation when there is not enough PV power, AD is switched off and EES has insufficient stored energy to meet the load demand; AD will then operate at minimum power output to meet the load demand. Any surplus energy generated from $\mathrm{AD}$ will be stored in EES.

An interesting research question to be explored is "how does the EES dispatch method will influence the cost of the system and its components?". To answer this, a SOC threshold is defined as $S O C_{\text {Threshold }}$ to classify the dispatch priority for EES and AD. The operating regime can be broken down into three phases as shown in Fig. 3, explained as follows:

Phase 1 (Blue): In the first phase, the SOC at time $t$ will be compared with the predefined $S O C_{\text {Threshold. }}$ If the SOC is greater than or equal to the threshold, then EES will be discharged first to meet the demand, given that the load is greater than the PV output. The power to be discharged is $P_{E E S_{S 1}}$. It is expected that a higher $S O C_{\text {Threshold }}$ will reduce energy spillage and surplus energy from PV will be better utilized. Less biogas will be used. However, more EES cycles will occur throughout the system lifetime due to excessive discharging. 
Phase 2 (Brown): The regime will determine if there is deficit power at the instance. If so, EES will be discharged to meet the load while satisfy the constraint. The power to be discharged is $P_{E E S_{S 2}}$. AD will be turned on to minimum output to meet the load if EES does not have enough stored energy. During this time, any surplus power from AD will be stored in EES.

Phase 3 (Red): This phase will calculate the energy to be stored from the surplus power from $\mathrm{AD}$ and $\mathrm{PV}$. 


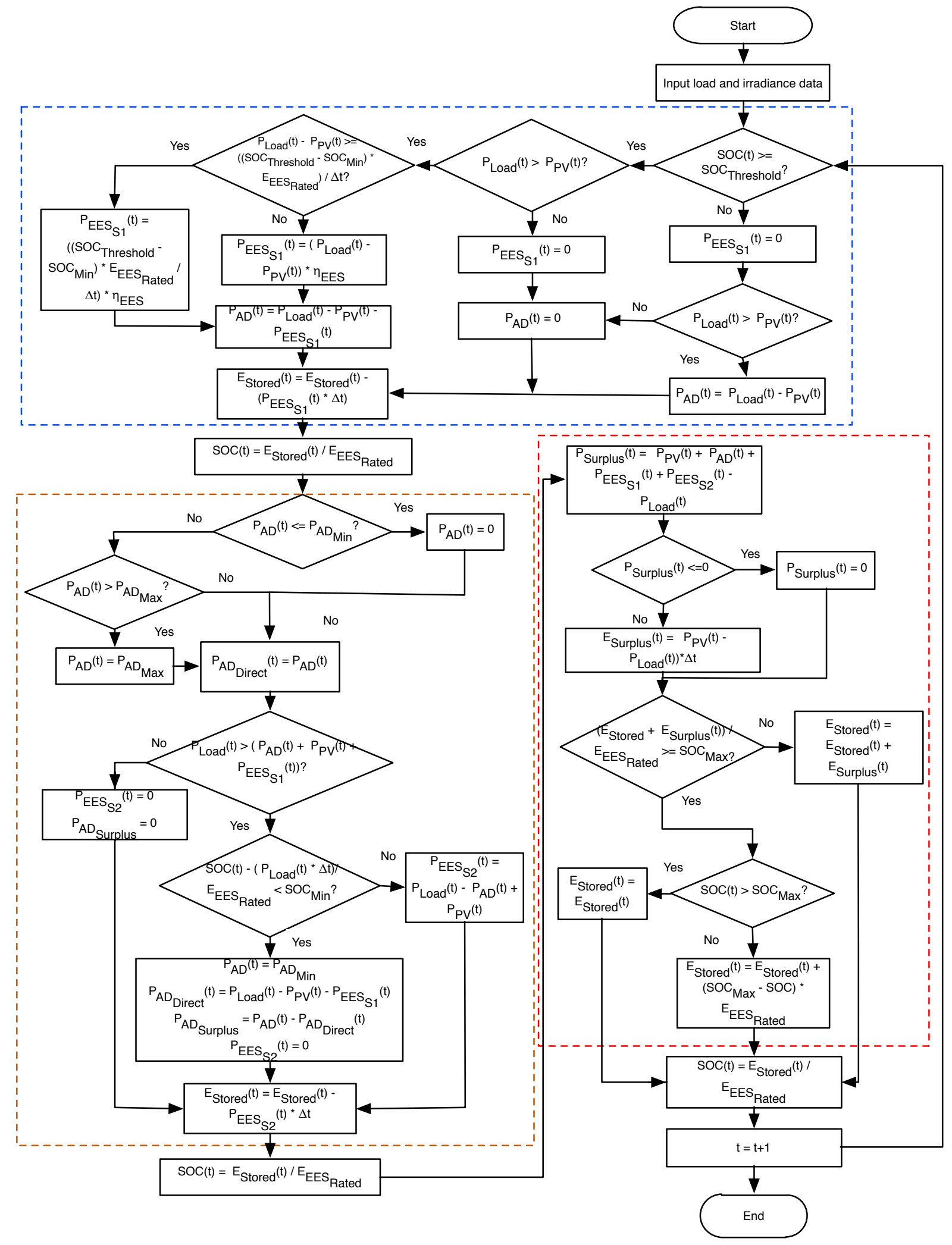

Fig. 3. Proposed hybrid system operating regime.

\subsection{Case study}

Case studies are conducted with MATLAB to verify the dispatch methods and operating regime. The studies are for $S O C_{\text {Threshold }}$ at $100 \%$, i.e. the EES will not have the priority to 
discharge over AD. Fig. 4 presents the results for 5 days of system operation in January. It can be seen that power curtailment has been applied to PV and the discarded surplus energy produced by PV is shown in green. At this point, the EES is fully charged. The EES is discharged to meet the power deficit, when PV output is increasing during sunrise and decreasing during sunset. The $\mathrm{AD}$ part loading constraint is triggered at these instances.
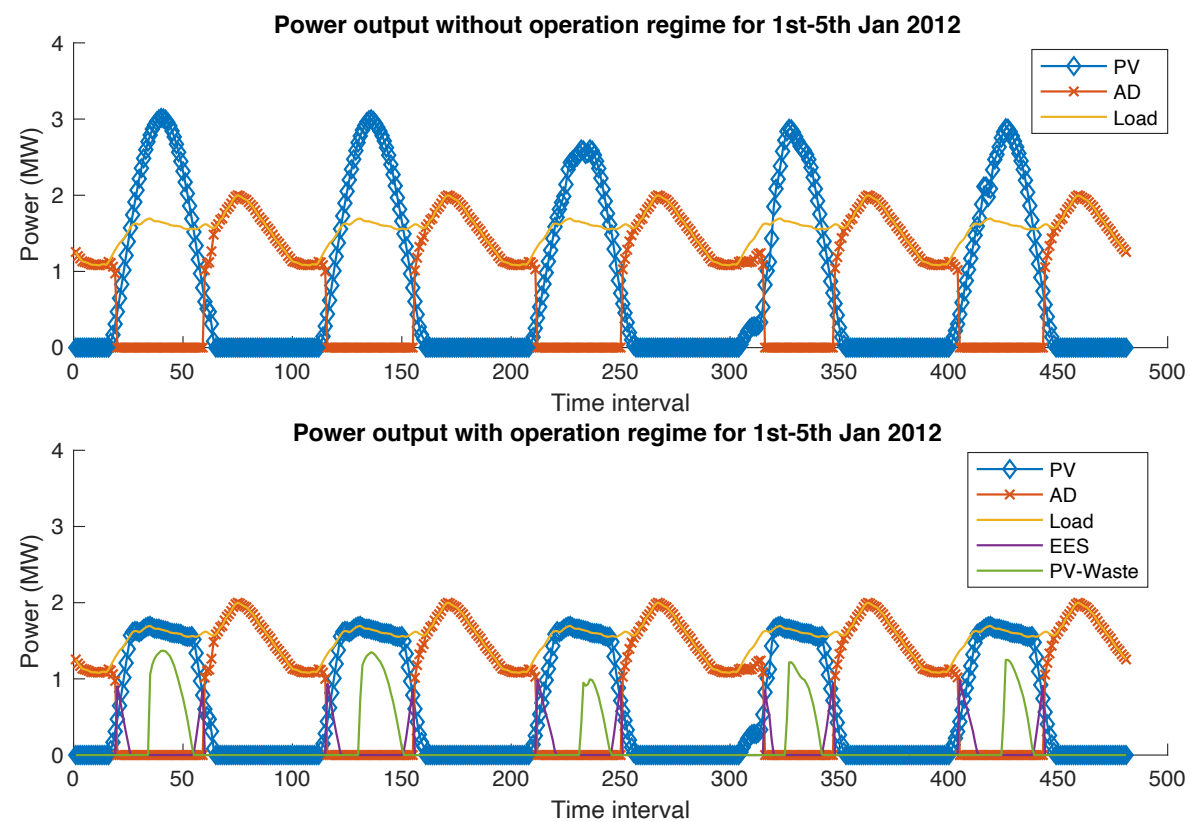

Fig. 4. System's power output for summer case.

Fig. 5 shows the simulation results for 5 days of system operation in November. As stated previously, November is the month with most repeated rain in the year. This will introduce severe fluctuations to the PV power output. All of the PV power is used during the time period, either to meet the demand directly or stored in EES. Due to the power deficit, there are instances where both AD and EES are used to meet the demand. It can be confirmed that the operation of the hybrid system is achieved with the proposed regime.
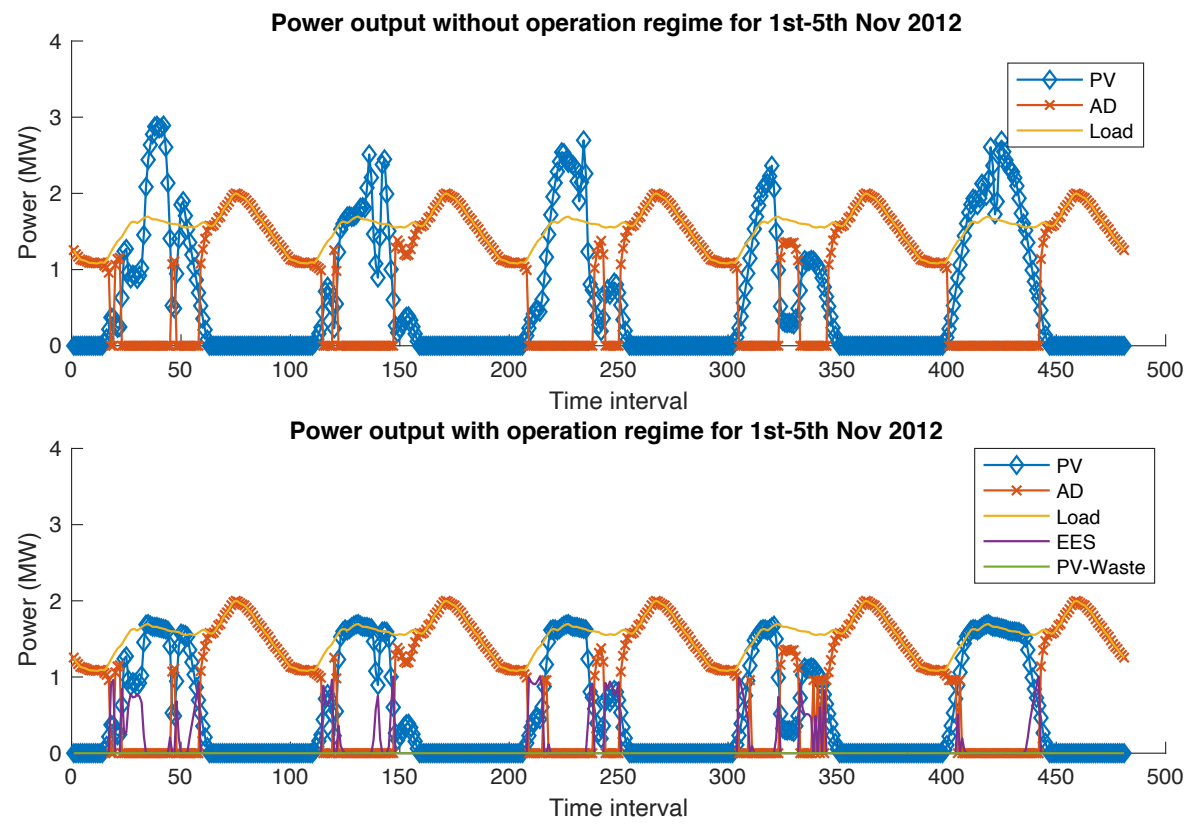

Fig. 5. System's power output for spring case. 
The SOC for the system with $S O C_{\text {Threshold }}$ at two extremes are presented in Fig. 6. It can be observed that deep discharges occur in Jan when $S O C_{\text {Threshold }}$ is set at $0 \%$. The solar power is better utilized, i.e. less energy spillage due to the storage is fully used at the beginning of the regime. Contrary to the case for $S O C_{\text {Threshold }}$ is set at $100 \%$ as shown in the adjacent figure, the SOC is rarely discharged and is kept at high SOC. Surplus power will be wasted, i.e. will not be stored as EES is full in most of the time.

For the case in November, the surplus power is not an issue as the EES is never fully charged. When $S O C_{\text {Threshold }}$ is set at $0 \%$, the SOC is mostly at minimum $0 \%$. This can be explained by the fact that the EES is used with priority, similar to the case in Jan with $S O C_{\text {Threshold }}$ at $0 \%$. The EES is less susceptible to full discharges when $S O C_{\text {Threshold }}$ is at $100 \%$. In general, the EES of a practical hybrid system will experience numerous partial cycles with different SOC ranges to fulfil the system energy requirement.
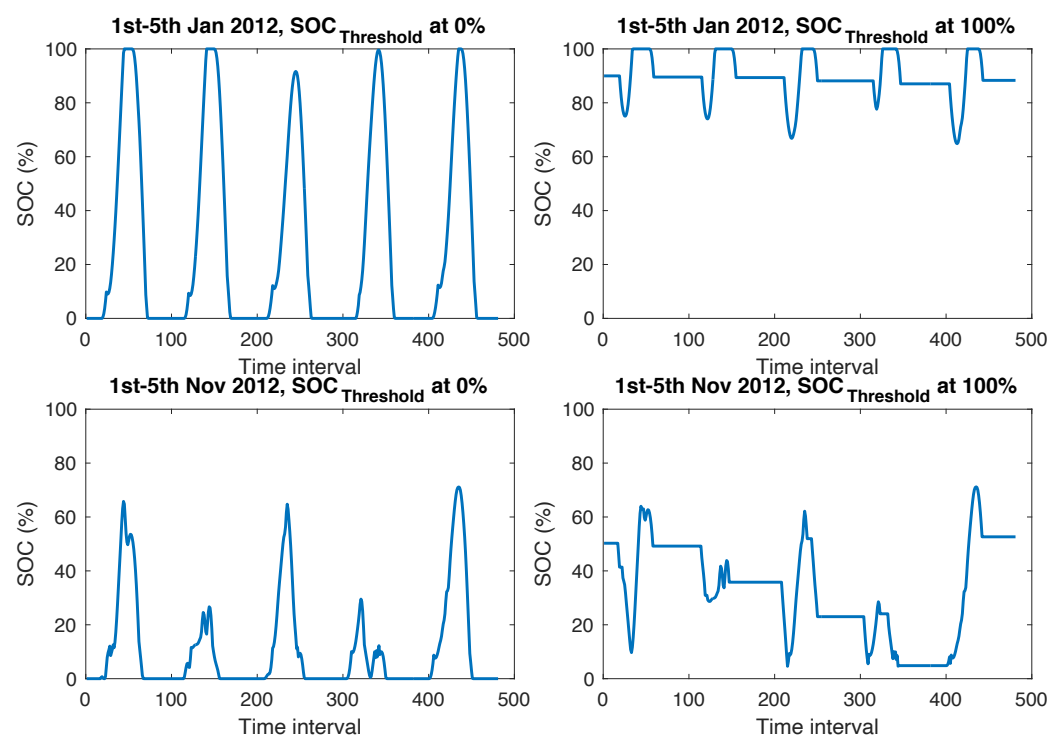

Fig. 6. EES SOC for $0 \%$ and $100 \%$ SOC Threshold in summer and spring cases.

A sensitivity analysis for $S O C_{\text {Threshold }}$ with steps at 0.01 , from 0 to 1 is carried out for the system's lifetime operation. The power output and SOC are stored for cost analysis and will be presented in Section 4.

\section{Economic analysis}

Apart from capital costs, there are operational costs associated with EES and AD. These can be separated into fixed and variable costs. For $\mathrm{AD}$, fixed operational costs include labour and routine generator maintenance. Fuel cost to produce electrical power is the variable operational costs for AD. The fixed operational cost for EES are the operation and maintenance (O\&M) costs, such as routine battery services. As stated in [37], identifying the operating cost for EES is challenging since it does not consume fuel unlike the AD source. The energy cost can be assigned to the EES to represent the cost for charging and act as the "fuel" cost. In addition to this, another variable operational cost should be included to model the degradation of EES due to charging and discharging. This is known as degradation cost and can be broken down into two types, the degradation cost per $\mathrm{kWh}$ and degradation cost per cycle.

\subsection{AD operational cost model}


The Caterpillar G3512E Genset [30] is adopted to model the biogas power plant, with a rated capacity of 1.2 MW. The cost for AD power generation is given in Equation (7).

$$
C_{A D_{\text {Fuel }}}(t)=C_{G a s} \cdot \frac{P_{A D}(t) \cdot\left[a \cdot P_{A D}^{2}(t)+b \cdot P_{A D}(t)+c\right]}{L H V}
$$

$C_{G a s}$ is the AD gas cost at $6.97 \$ / m c f$ [38], $L H V$ is the lower heating value at $905 \mathrm{btu} / \mathrm{ft} 3$ [30]. The fuel consumption is a quadratic function with constants $a, b$ and $c$ at $0.0016,-3.935$ and 10641 respectively. The fuel consumption curve is displayed in Fig. 7 and it shows an interesting relationship. The consumption is at the lowest when the power output is at the maximum. This is due to the generator achieves the highest operation efficiency at rated capacity. The generator set should be avoided to meet partial load demand, hence the constraint.

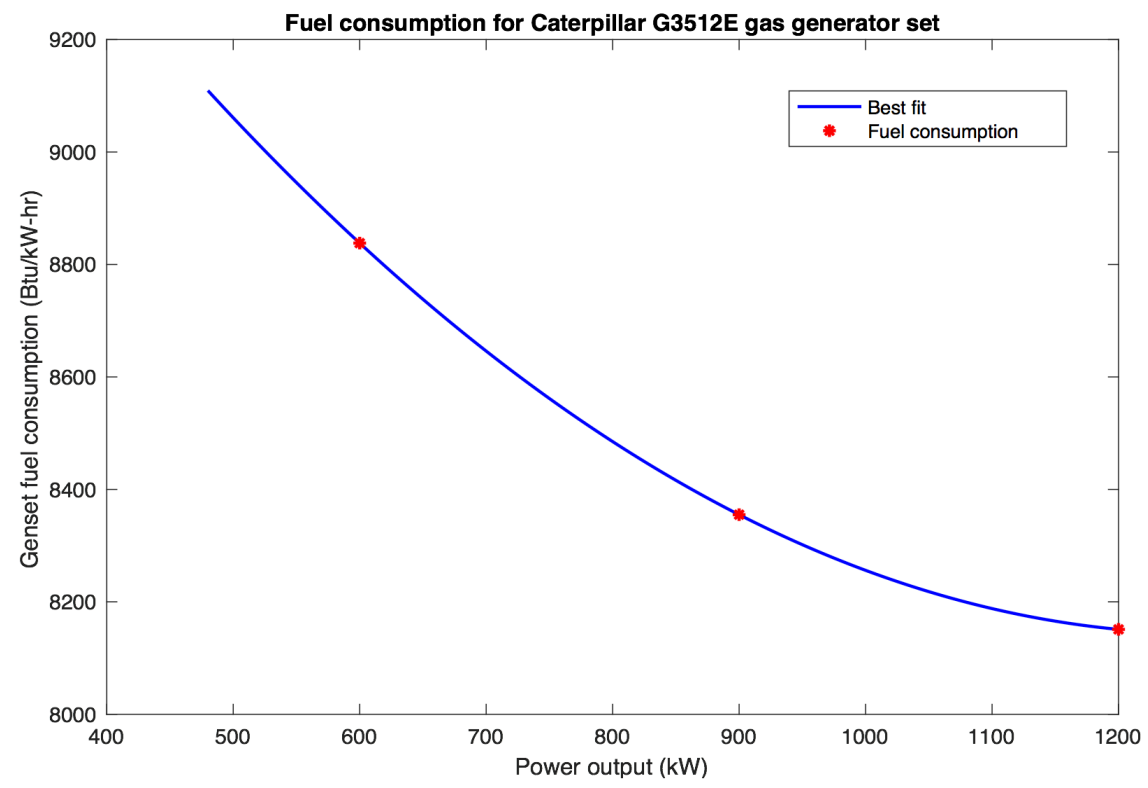

Fig. 7. Fuel consumption curve for $\mathrm{AD}[30]$.

\section{2. $\mathrm{LiCoO}_{2}$ degradation cost model and number of replacements}

In contrast to many research works which uses DOD or energy discharge content in $\mathrm{kWh}$ to calculate the EES degradation, this paper uses a capacity fade model to quantify the degradation costs. In recent years, there are published materials on the study in Li-ion capacity fading. The factors that are studied are mainly on DOD, discharge C-rate and operating temperature. In [39], the cycle life of a Graphite/ $\mathrm{LiFePO}_{4}$ battery was researched and subsequently, the cycle life models were built. Three parameters were studied, with six temperatures from $-30^{\circ} \mathrm{C}$ to $60^{\circ} \mathrm{C}$, five DODs from $10-90 \%$ and four C-rates ranging from $\mathrm{C} / 2$ to $10 \mathrm{C}$. A power law relationship was established between the capacity fade and the charge throughput, which represents the amount of charge delivered by EES during cycling. The highlight is that the capacity loss was mainly affected by temperature and time, while the effect of DOD was less of a concern with a C-rate of $\mathrm{C} / 2$.

The capacity loss rate of a Li-ion cell with nickel cobalt aluminium cathode under a restricted range (30-90\% SOC) and full discharge (0-100\% SOC) for two temperatures $\left(25^{\circ} \mathrm{C}\right.$ and $60^{\circ} \mathrm{C}$ ) were studied in [40]. It found that capacity fading can be reduced with a reduced 
SOC range. These can be explained by the formation of new resistance layer and the lack of contact between the primary particles with the micro-crack generation.

Further analysis in cycle life study with restricted range for Li-ion cell were conducted in [11] with Graphite/ $\mathrm{LiCoO}_{2}$ cells. It found that the capacity loss can be affected by the change in SOC $(\triangle S O C)$, mean SOC and C-rate. A power law model is developed for capacity fade of Graphite/LiCoO2 cells under different SOC ranges. Commented by the authors, the $\triangle S O C$ and mean SOC during operation should be minimized in order to decrease the long-term capacity fade rate, which results in higher number of equivalent cycles or increased cumulative discharge capacity throughout the EES lifetime. Also reported in [10], increased cycle life can be a result in cycling in lower charged states for Li-ion cells.

The degree of EES degradation is a function of number of cycles, change in SOC and amount of energy that flows throughout it [22]. The normalized discharge capacity model in [11] is adopted to study the degradation cost for EES. However, there are several limitations with the model. Firstly, it is not able to capture the unexpected capacity loss behaviour for low SOC ranges, such as $0-60 \%$ in the presented case study. However, the results show that the propose model gives the pessimistic results for the low SOC ranges. The experiment results for normalized discharge capacity with respected to the equivalent full cycle are above the fitted curve. It is expected that there will be more cycles than the computed result from the model, therefore the degradation should be less for low SOC ranges.

The second limitation is that in the study for complete discharge range i.e. $0-100 \%$ SOC, there is a sudden increase in capacity loss rate after 500 equivalent full cycles. This suggests that a new degradation mechanism is triggered and it is in a form of linear capacity fade model. To overcome this issue in our study, a function is fitted with the data points obtained from the normalized discharge capacity model with the number of equivalent full cycles for $100 \%$ DOD between $0-100 \%$ SOC. With inspection, this number is approximately 850 full cycles. The fitted function is shown in Fig. 8 and the data points generated from normalized discharge capacity model after 30\% DOD are neglected as it prevents the best fit to the $100 \%$ DOD. Also after $45 \%$ DOD, it shows an increase in cycle life which is unreasonable.

During a discharge cycle, the mean SOC is calculated with Equation (8) below:

$$
S O C_{\text {Mean }}=\frac{S O C_{\text {Upper }}+S O C_{\text {Lower }}}{2}=\frac{S O C_{t_{1}}+S O C_{t_{2}}}{2}
$$

$S O C_{\text {Upper }}$ is the SOC when discharge begins and $S O C_{\text {Lower }}$ is the SOC when charging begins for each partial cycle. The time $t_{1}$ is used to locate the time when the SOC is at the maximum of a cycle. The change in SOC is given in Equation (9) below:

$$
\triangle S O C=S O C_{\text {Upper }}-S O C_{\text {Lower }}
$$

The rated cycle life and $a_{e e s}$ are calculated with Equations (10) and (11) [11] respectively.

$$
\begin{gathered}
\text { Ratedcycle }_{\text {SOC }} \text { Upper }, \text { SOC }_{\text {Lower }}=e^{\frac{\ln \left(\frac{100^{0.453 *(100-N D C)}}{a_{e e s}}\right)}{0.453}} \quad \text { when } S O C_{\text {Upper }} \neq 100 \% \\
a_{\text {ees }}=3.25 * S O C_{\text {Mean }} *\left(1+3.25 * \Delta S O C-2.25 * \Delta S O C^{2}\right)
\end{gathered}
$$

where $N D C$ is the normalized discharge capacity at $80 \%$. The three-parameter equation in Equation $(12)[8,26]$ is used to fit the rated cycle for deep discharge situations and $S O C_{U p p e r}$ is at $100 \%$ during a discharge cycle. 
Ratedcycle $_{100 \%, S O C_{\text {Lower }}}=\frac{d_{\text {ees }}}{\left(D o D-e_{\text {ees }}\right)^{f_{e e s}}} \quad$ if SOC $_{\text {Upper }}=1 \& S O C_{\text {Lower }}<0.55$

where $d_{e e s}, e_{e e s}$ and $f_{e e s}$ are constants with values $1278,-0.36$ and 1.265 respectively.

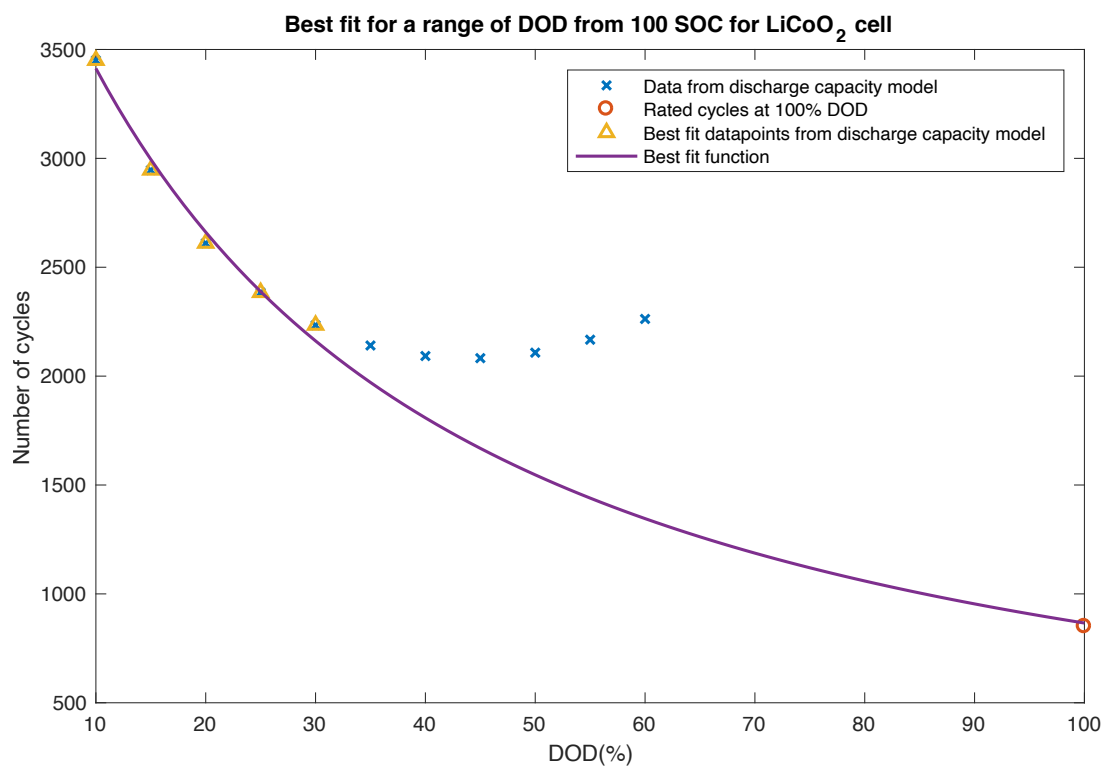

Fig. 8. $\mathrm{LiCoO}_{2}$ cycle life function for discharge from $100 \% \mathrm{SOC}$.

The purpose to calculate the degradation cost per cycle is to determine the number of EES lifetime replacements. The value for the whole EES is calculated and then the cost of every discharge cycle is recorded. The EES will need to be replaced once the max capital cost is reached [22]. The replacement cost per discharge cycle for year $i$ and cycle $k$ is calculated with Equation (13) and the number of lifetime replacements is calculated with Equation (14).

$$
\begin{aligned}
& C_{E E S_{\text {Replacement }}}(i, k)=\frac{C_{C a p_{E E S}} E_{E E S_{\text {Rated }}}}{\text { Ratedcycle }_{S O C_{\text {Upper }}, S O C_{\text {Lower }}}(i, k)} \\
& N_{E E S}=\frac{\sum_{i}^{n} \sum_{k}^{m} C_{E E S_{\text {Replacement }}}(i, k)}{C_{\text {Cap }} \text { EES }_{\text {EE }} \cdot E_{\text {EES }}}
\end{aligned}
$$

$C_{C a p_{E E S}}$ and $E_{E E S_{\text {Rated }}}$ are the capital cost and rated energy capacity of EES.

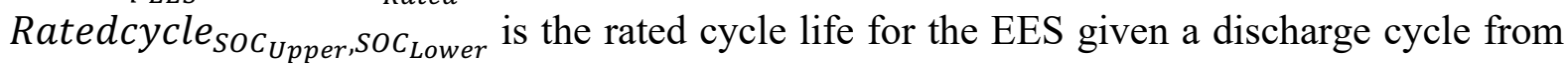
$S O C_{\text {Upper }}$ to $S O C_{\text {Lower. }}$. Fig. 9 shows a comparison of Li-ion cells with different chemistries for the cycle life under a range of DOD from $100 \% \mathrm{SOC}$. $\mathrm{LiCoO}_{2}$ cells have a shorter life span as compared to other chemistries and $\mathrm{LiFePO}_{4}$ can double the rated cycle life at low DODs [41]. A lower degradation per cycle and degradation per $\mathrm{kWh}$ can be achieved with a higher rated cycle life. 

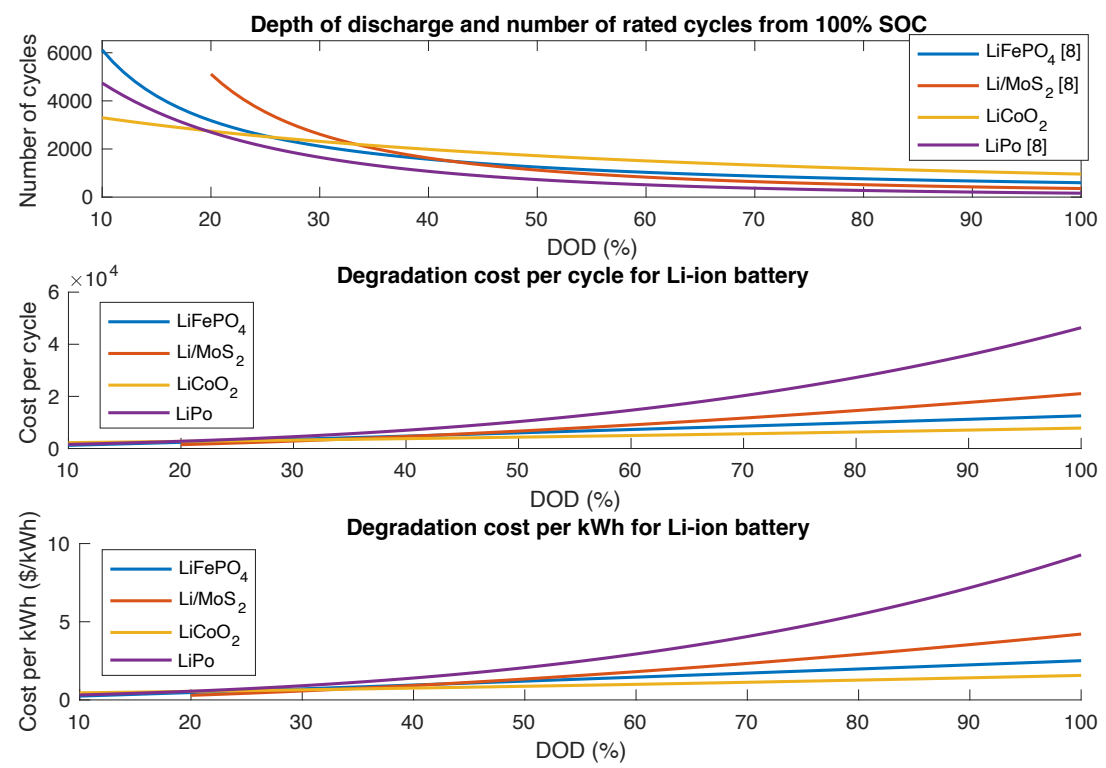

Fig. 9. Comparison of Li-ion EES degradation costs and cycle life for discharge from 100\% SOC.

A sensitivity analysis with a range of $S O C_{\text {Threshold }}$ has been performed on the system to study the required number of EES lifetime replacements. Fig. 10 displays the simulation results. Since the number of EES cannot be a fraction, the obtained result is rounded up to the nearest integer. The number of replacement increases as the $S O C_{\text {Threshold }}$ is reduced. To explain these phenomena, Fig. 11 provides the histogram for changes in SOC and SOC occurrences for the lifetime operation with $S O C_{\text {Threshold }}$ at $0 \%$ and $100 \%$. With $S O C_{\text {Threshold }}$ at $100 \%$, the SOCs are mostly situated in the higher region and results in a higher $S O C_{\text {Mean }}$. However, the total number of discharges, which is given by the integral of the number of occurrences for $\triangle S O C$, is less than for the case when $S O C_{\text {Threshold }}$ is at 0 . There are more deep discharges for the case with $S O C_{\text {Threshold }}$ at $0 \%$ as given by $\triangle S O C$. In summary, a $S O C_{\text {Threshold }}$ at $0 \%$ will generally on average result a lower $S O C_{\text {Mean }}$, but the increase in total number of discharges and the deep discharge cycles have a larger impact to the EES degradation and result in an increased number of EES replacements. 


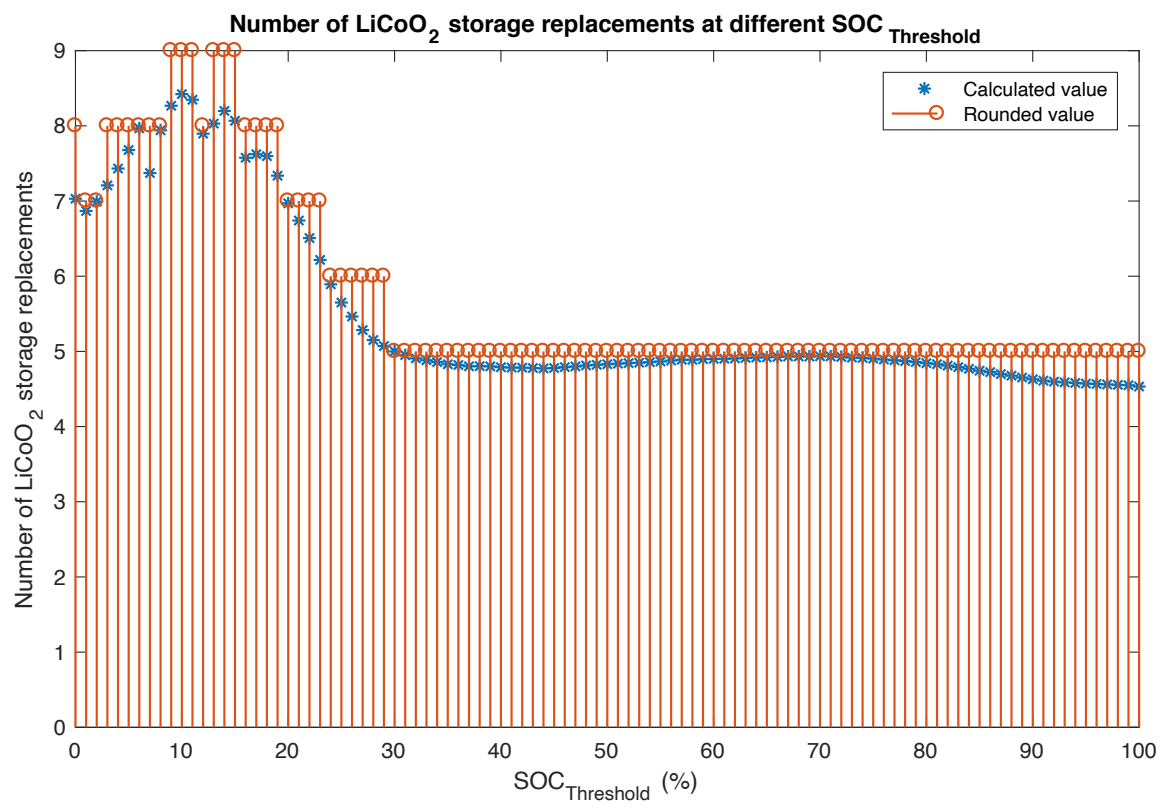

Fig. 10. Number of lifetime EES replacements for different $S O C_{\text {Threshold }}$.
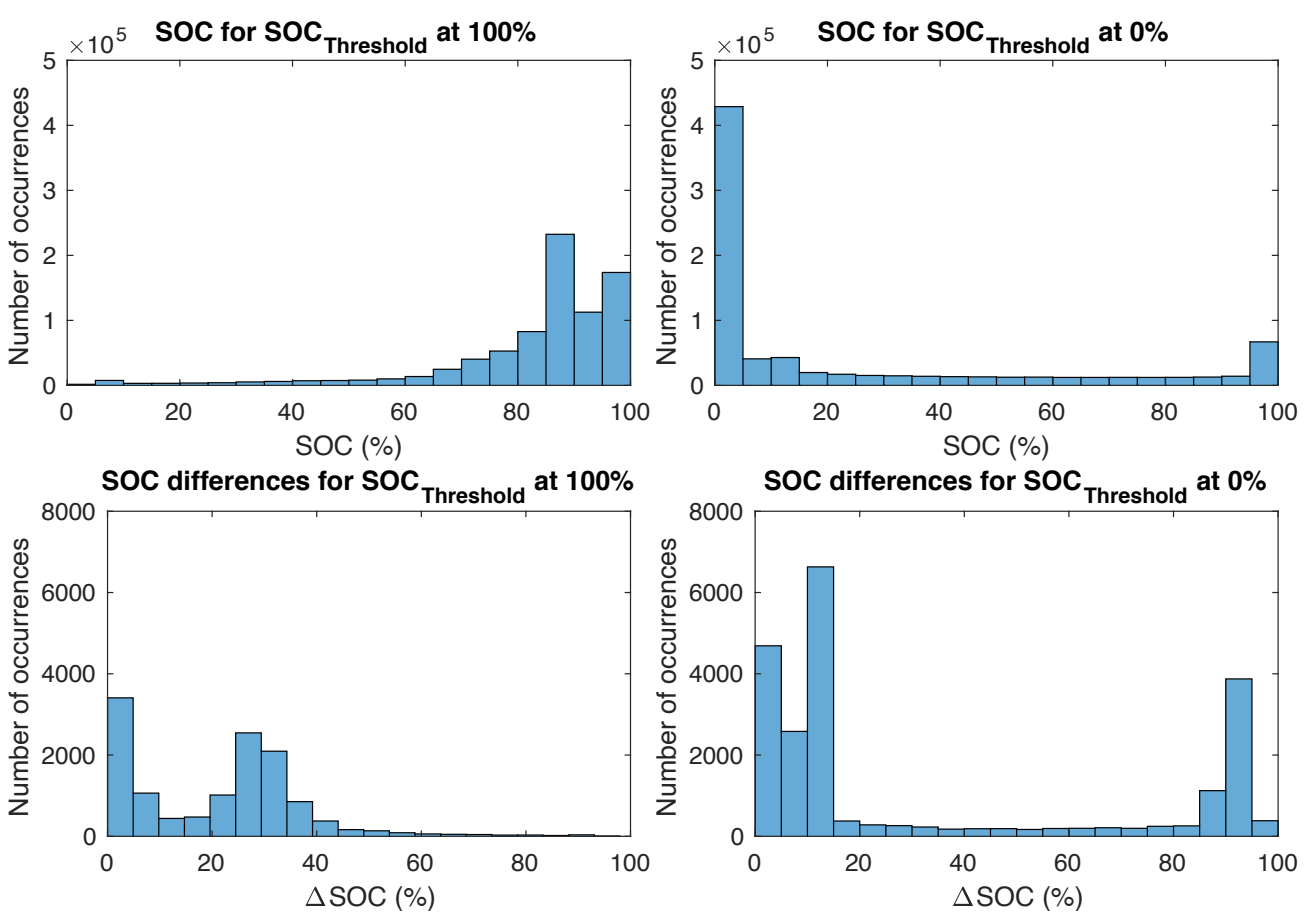

Fig. 11. System's lifetime SOCs and SOC differences for $S O C_{\text {Threshold }}$ at $0 \%$ and $100 \%$.

\subsection{Levelized cost of electricity derivation}

The LCOE for individual components and the system are studied with the established operational cost models for AD and EES. It is of crucial importance to understand the cost implications of how each generation asset and EES will react to the operating regime. The cost is largely affected by the asset lifetime electricity production, as well as the operational costs or degradation costs for the case with EES. The original definition of LCOE is given in Equation (15) [1, 17]. 


$$
\mathrm{LCOE}=\frac{\text { lifecycle cost }(\$)}{\text { lifetime energy production }(\mathrm{kWh})}=\frac{C_{C a p}+\sum_{i=0}^{n} C_{O \& M}(i) \cdot(1+d)^{-i}}{\sum_{i=0}^{n} E(i) \cdot(1+d)^{-i}}
$$

$C_{C a p}$ is the fixed capital cost of the asset and may include installation costs. $C_{O \& M}$ is the total operation and maintenance costs and $E$ is the total energy production, it is often given per year $i$ for asset lifetime $n$, and a discount rate $d$ needs to be included to account for the depreciation in value for costs and energy. The discount rate used for the studies is $8 \%$ [17].

\subsubsection{LCOE for PV}

The LCOE for PV can be calculated with Equations (16), (17) and (18) below:

$$
\begin{gathered}
\mathrm{LCOE}_{\mathrm{PV}}=\frac{C_{P V}}{E_{P V}} \\
C_{P V}=N_{P V} \cdot\left(C_{C a p_{P V}}+C_{\text {Inst }_{P V}}\right)+\sum_{i=0}^{n} \frac{N_{P V} \cdot C_{P V_{\text {O\&M }} \text { Fixed }}}{(1+d)^{i}} \\
E_{P V}=\sum_{i=0}^{n} \frac{(1-\sigma)^{i} \cdot \sum_{j=1}^{t} P_{P V_{\text {Direct }}}(i, j)+P_{P V_{\text {Store }}}(i, j)}{(1+d)^{i}}
\end{gathered}
$$

$C_{C a p_{P V}}, C_{I n s t_{P V}}$, and $C_{P V_{O \& M_{F i x e d}}}$ are the capital, installation, and operation and maintenance costs respectively for PV. $\sigma$ is the annual degradation constant for the PV panel at $0.5 \%$ [17]. $P_{P V_{\text {Direct }}}$ and $P_{P V \text { Store }}$ are the power output from PV that is used to meet the demand and to be stored in EES respectively, at hour $j$ and year $i$. Since the system is an offgrid system, the wasted energy from PV generator, i.e. not used directly to meet the demand or stored in EES is not included in the lifetime energy production as the generated electricity will not be sold and the cost cannot be recovered, resulting a higher levelized cost.

\subsubsection{LCOE for AD}

The LCOE for AD can be calculated with Equations (19), (20), (21) and (22) below:

$$
\begin{gathered}
\mathrm{LCOE}_{\mathrm{AD}}=\frac{C_{A D}}{E_{A D}} \\
C_{A D}=C_{\text {Cap }_{A D}}+\sum_{i=0}^{n} \frac{C_{A D_{O \& M_{\text {Fixed }}}} \cdot P_{A D_{\text {Max }}}+\sum_{j=1}^{t} C_{A D_{O \& M_{\text {Var }}}}(i, j)}{(1+d)^{i}}
\end{gathered}
$$

$C_{C a p_{A D}}$ and $C_{A D_{O \& M_{F i x e d}}}$ are the capital and fixed annual O\&M costs for AD. The variable operation and maintenance cost for $\mathrm{AD}, C_{A D_{O \& M_{V a r}}}$, is calculated with Equation (21) below:

$$
C_{A D_{\text {O\&M }} \text { Var }}(i, j)=C_{A D_{\text {Fuel }}}(i, j)+\left(C_{A D_{\text {Labour }}} / 2\right) \cdot P_{A D} \Delta t(i, j)
$$

$C_{A D_{\text {Labour }}}$ is the labour cost for operating the $\mathrm{AD}$ at $\$ 0.05 / \mathrm{kWh}$ [32]. The $\mathrm{AD}$ lifetime energy production at present value is calculated with Equation (22) below: 


$$
E_{A D}=\sum_{i=0}^{n} \frac{\sum_{j=1}^{t} P_{A D_{\text {Direct }}}(i, j)+P_{A D_{\text {Store }}}(i, j)}{(1+d)^{i}}
$$

$P_{A D_{\text {Direct }}}$ is the AD power output that is used to meet the demand directly and $P_{A D_{\text {store }}}$ is the surplus power from $\mathrm{AD}$ that is produced while meeting the deficit demand.

\subsubsection{Levelized cost of storage (LCOS)}

Recently, the term LCOS has received attention in both the industry and academia [42, 43]. Since EES can provide a diverse range of services for power systems operation, e.g. frequency support, renewable integration, uninterruptible power supply, it is of significant interest in studying the cost effectiveness of deploying a specific type of EES, such as lead-acid, Li-ion etc. to perform certain tasks. LCOS has similar attributes to LCOE and is given by Equation (23) below:

$$
\begin{aligned}
& \mathrm{LCOS}=\frac{C_{E E S}}{E_{E E S}} \\
& C_{E E S}=C_{C a p_{E E S}} . E_{E E S_{\text {Rated }}}+\sum_{i=0}^{n} \frac{C_{E E S_{O \& M_{T o t a l}}}}{(1+d)^{i}}
\end{aligned}
$$

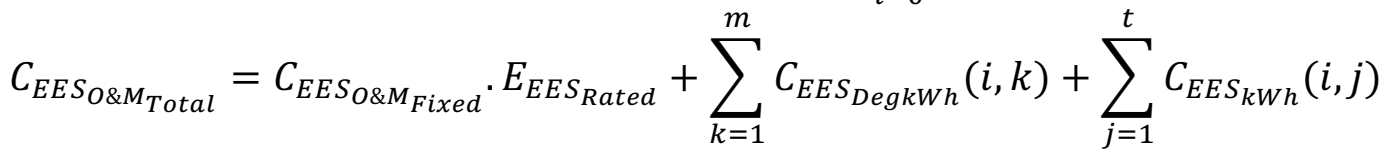

$C_{E E S_{O \& M_{F i x e d}}}$ is the fixed annual EES O\&M cost. The variable operational costs for EES include the degradation per kWh cost and energy cost are calculated with Equations (26) and (27) respectively. $m$ is the number of discharge cycles per year.

$$
\begin{gathered}
C_{E E S_{\text {DegkWh }}}(i, k)=\frac{C_{C a p_{E E S}}}{\text { Ratedcycle }_{S o C_{U p p e r}, S o C_{\text {Lower }}}(i, k)} \cdot\left[\operatorname{SOC}_{\text {Upper }}(i, k)-\operatorname{SOC}_{\text {Lower }}(i, k)\right] \cdot E_{E E S_{\text {Rated }}} \\
C_{E E S_{k W h}}(i, j)=C_{E E S_{O \& M_{\text {Var }}}} \cdot E_{E E S_{\text {Store }}}(i, j)
\end{gathered}
$$

$C_{E E S_{O \& M_{V a r}}}$ is the variable O\&M cost for the energy $E_{E E S_{S t o r e}}$ to be stored in EES. The lifetime electricity production is calculated with Equation (28) below:

$$
E_{E E S}=\eta_{E E S} \sum_{i=0}^{n} \frac{\sum_{j=1}^{t}\left[E_{E E S-S 1}(i, j)+E_{E E S-S 2}(i, j)\right]}{(1+d)^{i}}
$$

$\eta_{E E S}$ is the round-trip efficiency of EES at $90 \%$ for Li-ion.

\subsubsection{Levelized cost of delivery (LCOD)}

Since EES is a storage device and is not a conventional electrical energy generating source, i.e. the asset does not generate electricity from primary energy source, it is necessary to take account of the cost for the energy conversion process from the primary form, i.e. solar irradiance or biomass into electricity. This is studied in [17] and the term LCOD was proposed. Equation (29) gives the LCOD for the system. 


$$
\mathrm{LCOD}=\frac{C_{E E S}+C_{P V_{\text {Storetotal }}}+C_{\text {Con }}+C_{A D_{\text {Storetotal }}}}{E_{E E S}}
$$

The charge controller cost is given in Equation (30) below:

$$
\begin{gathered}
C_{\text {Con }}=N_{\text {Con }} \cdot\left(C_{\text {Cap }}+C_{\text {Con }}+{ }_{\text {Inson }}\right)+\sum_{i=0}^{n} \frac{C_{O \& M_{\text {Con }} \cdot} \cdot N_{\text {Con }}}{(1+d)^{i}} \\
N_{\text {Con }}=\operatorname{ceil}\left(\frac{P_{P V_{\text {Rated }}}}{P_{\text {Con }}}\right) \cdot N_{\text {Con-rep }}
\end{gathered}
$$

$N_{\text {Con }}$ is the number of controllers; $C_{C a p_{C o n}}, C_{I n s t}$ Con and $C_{O \& M_{C o n}}$ are the capital, installation and O\&M costs for the controller. The ceil function converts the number of controllers into the nearest integer above. $N_{\text {Con-rep }}$ is 2 and is the number of controller replacements during the system's lifetime [1]. $P_{P V_{\text {Rated }}}$ and $P_{C o n}$ are the rated power output for the PV farm and the controller respectively. The cost for producing the electricity from AD to be stored in EES is given in Equations (32) below:

$$
\begin{gathered}
C_{A D_{\text {Storetotal }}}=C_{C_{\text {Cap }} A D}+\sum_{i=0}^{n} \frac{C_{A D_{O \& M_{F i x e d}}} \cdot P_{A D_{\text {Max }}}+\sum_{j=1}^{t} C_{A D_{O \& M_{\text {Store }}}}(i, j)}{(1+d)^{i}} \\
C_{A D_{\text {O\&M Store }}}(i, j) \stackrel{=}{=} C_{A D_{\text {Fuel }}}(i, j)+C_{A D_{\text {Labour }}} \cdot P_{A D_{\text {Store }}}(i, j)
\end{gathered}
$$

$P_{A D_{\text {Store }}}$ is the power generated from AD to be stored in EES as energy, the cost for producing the electricity from PV to be stored in EES is given in Equations (34) below:

$$
\begin{gathered}
\left.C_{P V_{\text {Storetotal }}=N_{P V} \cdot\left(C_{\text {Cap }}+C_{\text {Inst }}\right)}\right)+\sum_{i=0}^{n} \frac{\sum_{j=1}^{t} N_{\text {Store }}(i, j) \cdot C_{\text {O\&M } M_{P V i n t}}(i, j)}{(1+d)^{i}} \\
N_{\text {Store }}(i, j)=\frac{P_{P V_{\text {Store }}}(i, j)}{\varepsilon(i, j) \cdot \eta_{P V}}
\end{gathered}
$$

$N_{\text {Store }}$ is the PV panel area that is used to produce the surplus electricity for storage. The maintenance cost per hour for PV is calculated in Equation (36) below:

$$
C_{O \& M_{P V i n t}}(i, j)=\frac{C_{O \& M_{P V}}(i, j)}{365 * 24}
$$

\subsubsection{LCOE for system}

The system's LCOE is derived in Equation (37). It takes account of the total costs for operating the system and the energy output to meet the load demand.

$$
\begin{array}{r}
\mathrm{LCOE}_{\text {system }}=\frac{C_{P V}+C_{E E S}+C_{C o n}+C_{I n v}+C_{A D}}{E_{E E S}+E_{P V_{\text {Directtotal }}}+E_{A D_{\text {Directtotal }}}} \\
C_{\text {Inv }}=N_{\text {Inv }}\left(C_{\text {Cap Inv }}+C_{\text {Inst }}\right)+\sum_{i=0}^{n} \frac{C_{O \& M_{\text {Inv }}}(i) \cdot N_{\text {Inv }}}{(1+d)^{i}}
\end{array}
$$


$C_{C a p_{I n v}} C_{I n s t}$ Inv and $C_{O \& M_{I n v}}$ are the capital, installation and O\&M costs for the bidirectional inverter. The number of required inverters is calculated with Equation (39) below:

$$
N_{i n v}=\operatorname{ceil}\left(\frac{P_{P V_{R a t e d}}}{P_{I n v}}\right) \cdot N_{I n v-r e p}
$$

$P_{I n v}$ is the rated capacity of the inverter. $N_{I n v-r e p}$ is 2 and is the number of inverter replacements during the system's lifetime [1]. The total energy produced by PV and AD during the operation of the system that is used to meet the load demand directly are given in Equations (40) and (41) respectively as shown below:

$$
\begin{gathered}
E_{P V_{\text {Directtotal }}}=\sum_{i=0}^{n} \frac{(1-\sigma)^{i} \cdot \sum_{j=1}^{t} P_{P V_{\text {Direct }}}(i, j)}{(1+d)^{i}} \\
E_{A D_{\text {Directtotal }}}=\sum_{i=0}^{n} \frac{\sum_{j=1}^{t} P_{A D_{\text {Direct }}}(i, j)}{(1+d)^{i}}
\end{gathered}
$$

$P_{P V_{\text {Direct }}}$ and $P_{A D_{\text {Direct }}}$ are the power generated from $\mathrm{PV}$ and $\mathrm{AD}$ respectively for direct consumption.

\subsection{LCOE analyses and discussion}

The LCOE results with $S O C_{\text {Threshold }}$ at different values are displayed in Fig. 12. The cost for AD is lower when $S O C_{\text {Threshold }}$ is at a higher value. This is due to AD has a higher dispatch priority than EES and more electricity is generated from AD. The cost for EES will increase as a result of a decreased energy output. LCOD has a similar curve to LCOS, but with a larger cost. As explained previously, LCOD takes account of the energy conversion costs from primary source to electricity for storage. The capital costs for $\mathrm{AD}$ and $\mathrm{PV}$ has a large contribution to the actual energy storage costs. The cost for PV increases as $S O C_{\text {Threshold }}$ increases, this is due to less energy delivered by EES, produced from PV is used to meet the load demand. Taking all the costs and electricity generation into consideration, it is more economical to have the $S O C_{\text {Threshold }}$ at maximum value and to run the system at minimum costs. 

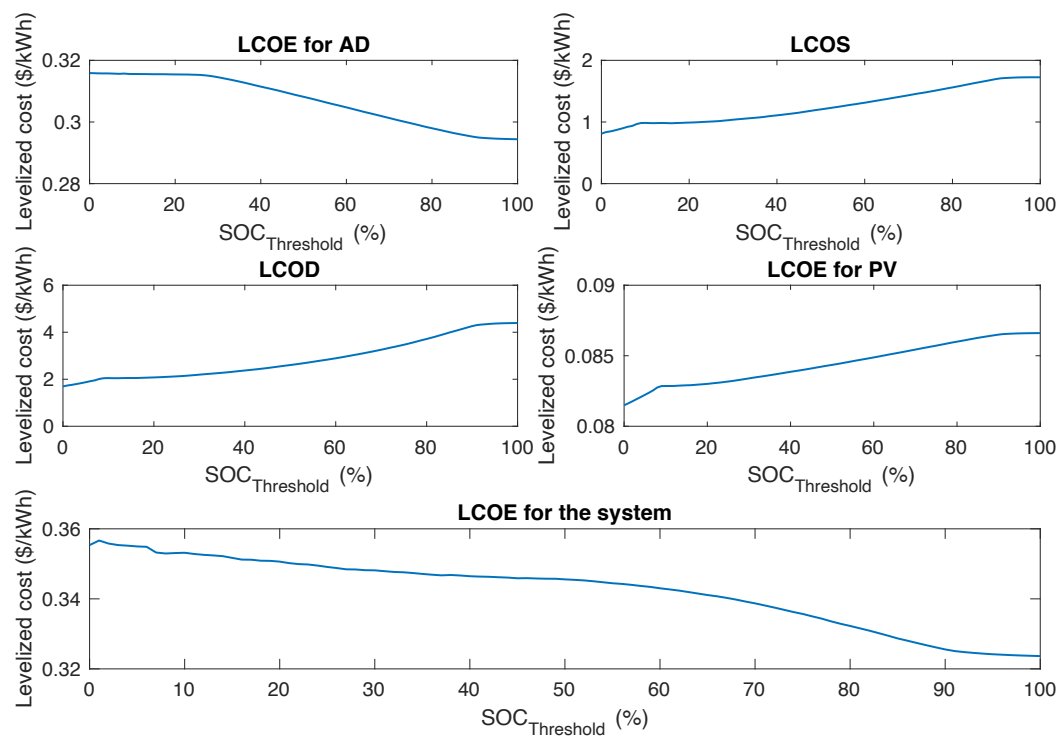

Fig. 12. LCOE for AD, EES and system at different $S O C_{\text {Threshold }}$ values.

Due to the excellent round-trip efficiency, high energy density and high power density, it is expected that $\mathrm{Li}$-ion batteries will be widely used in renewable hybrid systems [44]. However, the capital costs such as manufacturing and the cost of cobalt in cathodes are the major factors that prevent the wide-scale adoption at present. As discussed in [45], it is possible for Li-ion batteries to have a capital cost of $200 \$ / \mathrm{kWh}$ by 2020 . As such, Fig. 13 presents the results for the system LCOE with a sensitivity analysis on the EES capital cost.
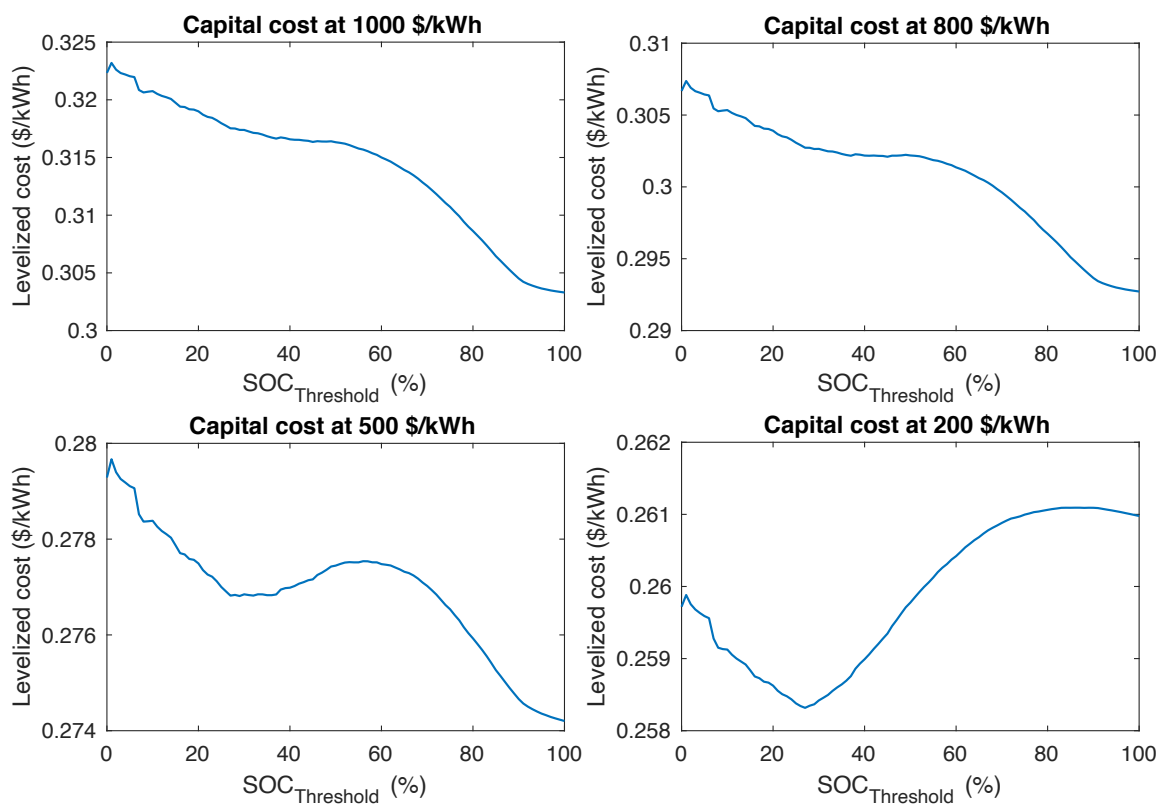

Fig. 13. System LCOE with different EES capital costs.

At $1000 \$ / \mathrm{kWh}$, the system cost is reduced as compared to the original study at $1500 \$ / \mathrm{kWh}$. As the capital cost decreases, it can be observed that the differences in levelized cost are minimized with $S O C_{\text {Threshold }}$ variation. This signifies that the cost of EES degradation has less influence to the system's cost. At $200 \$ / \mathrm{kWh}$, the largest difference in system's levelized cost is $0.0028 \$ / \mathrm{kWh}$. The lowest levelized cost for the system is achieved with a $S O C_{\text {Threshold }}$ at 
$33 \%$. It is more cost effective to cycle the EES more often and utilized the surplus PV energy than meeting the load demand with biogas. In future work, the carbon emission cost can be included in the cost generation for the analysis. Although biogas is seen as a renewable energy source, it still generates little amount of carbon emission due to the combustion process.

\section{Conclusions}

This work provides a techno-economic analysis of an off-grid photovoltaic, anaerobic digestion biogas power plant (AD) renewable energy system with Graphite/ $\mathrm{LiCoO}_{2}$ storage. The highlight of this work is that the accuracy of degradation costs for electrical energy storage (EES) is enhanced by utilizing a capacity fade model, by obtaining the cycle life on partial state of charge (SOC) range cycling. This research opens a range of research opportunities and future work to be conducted, listed as follows:

1. At present, most EES degradation effects focus on the discharging phase, i.e. depth of discharge and energy delivered by EES. The degradation effect due to charging phase should also be given;

2. The optimization problem formulations for power system with EES should be modified to incorporate capacity fade model;

3. Temperature [46] and C-rate should be included in the capacity fade model to provide a more realistic analysis;

4. For illustration purposes, the proposed regime is of static nature. The variable to control the dispatch priority of EES and $\mathrm{AD}, S O C_{\text {Threshold, }}$, can be of dynamic nature to minimize the system lifetime cost. This may need generation and load forecasting.

5. More studies in partial SOC ranges is required in order to build cell degradation model for all possible SOC ranges.

6. Capacity fade model for dynamic SOC cycling conditions, i.e. the cycle life due to a combination of different SOC ranges is needed.

Based on the results obtained in this study, it shows that the Graphite $/ \mathrm{LiCoO}_{2}$ is cost competitive compared to the dispatchable generator, i.e. AD biogas generator to provide electricity as the capital cost reduces to $200 \$ / \mathrm{kWh}$.

\section{Acknowledgements}

This research work was supported in part by the Guangdong University of Technology, Guangzhou, China under Grant from the Financial and Education Department of Guangdong Province 2016[202]: Key Discipline Construction Programme; in part by the Education Department of Guangdong Province: New and Integrated Energy System Theory and Technology Research Group, Project Number 2016KCXTD022; and in part by The Hong Kong Polytechnic University, Hong Kong China under the Incoming Visiting Ph.D. Students Programme.

\section{References}

[1] C. S. Lai and M. D. McCulloch, "Sizing of stand-alone solar PV and storage system with anaerobic digestion biogas power plants," IEEE Transactions on Industrial Electronics, vol. 64, pp. 2112-2121, 2017. 
[2] R. K. Akikur, R. Saidur, H. W. Ping, and K. R. Ullah, "Comparative study of standalone and hybrid solar energy systems suitable for off-grid rural electrification: A review," Renewable and Sustainable Energy Reviews, vol. 27, pp. 738-752, 2013.

[3] T. Tezer, R. Yaman, and G. Yaman, "Evaluation of approaches used for optimization of stand-alone hybrid renewable energy systems," Renewable and Sustainable Energy Reviews, vol. 73, pp. 840-853, 2017.

[4] J. L. Bernal-Agustín and R. Dufo-López, "Simulation and optimization of stand-alone hybrid renewable energy systems," Renewable and Sustainable Energy Reviews, vol. 13, pp. 2111-2118, 2009.

[5] F. Kazhamiaka, C. Rosenberg, and S. Keshav, "Practical strategies for storage operation in energy systems: design and evaluation," IEEE Transactions on Sustainable Energy, vol. 7, pp. 1602-1610, 2016.

[6] W. Su, J. Wang, and J. Roh, "Stochastic energy scheduling in microgrids with intermittent renewable energy resources," IEEE Transactions on Smart Grid, vol. 5, pp. 1876-1883, 2014.

[7] B. Zhou, X. Liu, Y. Cao, C. Li, C. Y. Chung, and K. W. Chan, "Optimal scheduling of virtual power plant with battery degradation cost," IET Generation, Transmission \& Distribution, vol. 10, pp. 712-725, 2016.

[8] Z. Zhang, J. Wang, and X. Wang, "An improved charging/discharging strategy of lithium batteries considering depreciation cost in day-ahead microgrid scheduling," Energy Conversion and Management, vol. 105, pp. 675-684, 2015.

[9] Y. Zheng, Z. Y. Dong, F. J. Luo, K. Meng, J. Qiu, and K. P. Wong, "Optimal allocation of energy storage system for risk mitigation of DISCOs with high renewable penetrations," IEEE Transactions on Power Systems, vol. 29, pp. 212-220, 2014.

[10] H. de Vries, T. T. Nguyen, and B. O. het Veld, "Increasing the cycle life of lithium ion cells by partial state of charge cycling," Microelectronics Reliability, vol. 55, pp. 22472253, 2015.

[11] S. Saxena, C. Hendricks, and M. Pecht, "Cycle life testing and modeling of graphite/LiCoO 2 cells under different state of charge ranges," Journal of Power Sources, vol. 327, pp. 394-400, 2016.

[12] A. Hoke, A. Brissette, K. Smith, A. Pratt, and D. Maksimovic, "Accounting for lithiumion battery degradation in electric vehicle charging optimization," IEEE Journal of Emerging and Selected Topics in Power Electronics, vol. 2, pp. 691-700, 2014.

[13] A. Yoshida, T. Sato, Y. Amano, and K. Ito, "Impact of electric battery degradation on cost-and energy-saving characteristics of a residential photovoltaic system," Energy and Buildings, vol. 124, pp. 265-272, 2016.

[14] M. G. Ippolito, M. L. Di Silvestre, E. R. Sanseverino, G. Zizzo, and G. Graditi, "Multiobjective optimized management of electrical energy storage systems in an islanded network with renewable energy sources under different design scenarios," Energy, vol. 64, pp. 648-662, 2014.

[15] A. T. D. Perera, V. M. Nik, D. Mauree, and J.-L. Scartezzini, "Electrical hubs: An effective way to integrate non-dispatchable renewable energy sources with minimum impact to the grid," Applied Energy, vol. 190, pp. 232-248, 2017.

[16] J. Sachs and O. Sawodny, "A two-stage model predictive control strategy for economic diesel-pv-battery island microgrid operation in rural areas," IEEE Transactions on Sustainable Energy, vol. 7, pp. 903-913, 2016.

[17] C. S. Lai and M. D. McCulloch, "Levelized cost of electricity for solar photovoltaic and electrical energy storage," Applied Energy, vol. 190, pp. 191-203, 2017. 
[18] A.-S. Hamedi and A. Rajabi-Ghahnavieh, "Explicit degradation modelling in optimal lead-acid battery use for photovoltaic systems," IET Generation, Transmission \& Distribution, vol. 10, pp. 1098-1106, 2016.

[19] E. Hittinger, T. Wiley, J. Kluza, and J. Whitacre, "Evaluating the value of batteries in microgrid electricity systems using an improved Energy Systems Model," Energy Conversion and Management, vol. 89, pp. 458-472, 2015.

[20] E. Telaretti, G. Graditi, M. Ippolito, and G. Zizzo, "Economic feasibility of stationary electrochemical storages for electric bill management applications: the Italian scenario," Energy Policy, vol. 94, pp. 126-137, 2016.

[21] G. Graditi, M. Ippolito, E. Telaretti, and G. Zizzo, "Technical and economical assessment of distributed electrochemical storages for load shifting applications: An Italian case study," Renewable and Sustainable Energy Reviews, vol. 57, pp. 515-523, 2016.

[22] C. Bordin, H. O. Anuta, A. Crossland, I. L. Gutierrez, C. J. Dent, and D. Vigo, "A linear programming approach for battery degradation analysis and optimization in offgrid power systems with solar energy integration," Renewable Energy, vol. 101, pp. 417430, 2017.

[23] C. Budischak, D. Sewell, H. Thomson, L. Mach, D. E. Veron, and W. Kempton, "Costminimized combinations of wind power, solar power and electrochemical storage, powering the grid up to $99.9 \%$ of the time," Journal of Power Sources, vol. 225, pp. 60-74, 2013.

[24] A. S. Hassan, L. Cipcigan, and N. Jenkins, "Optimal battery storage operation for PV systems with tariff incentives," Applied Energy, vol. 203, pp. 422-441, 2017.

[25] R. Rajbongshi, D. Borgohain, and S. Mahapatra, "Optimization of PV-biomass-diesel and grid base hybrid energy systems for rural electrification by using HOMER," Energy, vol. 126, pp. 461-474, 2017.

[26] Y. Zhang, A. Lundblad, P. E. Campana, F. Benavente, and J. Yan, "Battery sizing and rule-based operation of grid-connected photovoltaic-battery system: A case study in Sweden," Energy Conversion and Management, vol. 133, pp. 249-263, 2017.

[27] S. Mandelli, C. Brivio, E. Colombo, and M. Merlo, "A sizing methodology based on Levelized Cost of Supplied and Lost Energy for off-grid rural electrification systems," Renewable Energy, vol. 89, pp. 475-488, 2016.

[28] "NASA surface meteorology and solar energy," NASA, [Online]. Available: https://eosweb.larc.nasa.gov/cgi-bin/sse/grid.cgi. [Accessed: 28.08.2017].

[29] A. S. Mundada, K. K. Shah, and J. Pearce, "Levelized cost of electricity for solar photovoltaic, battery and cogen hybrid systems," Renewable and Sustainable Energy Reviews, vol. 57, pp. 692-703, 2016.

[30] "G3512E Caterpillar Gas engine technical data, Ref. Data Set DM8811-06-001," Industrial motor power corporation, 2013. [Online]. Available: http://attachments.impcorporation.com/21373414/Performance Data G3512E.pdf. [Accessed: 28.08.2017].

[31] A. Hassan, M. Saadawi, M. Kandil, and M. Saeed, "Modified particle swarm optimisation technique for optimal design of small renewable energy system supplying a specific load at Mansoura University," IET Renewable Power Generation, vol. 9, pp. 474-483, 2015.

[32] "CREST Cost of Energy Model: Anaerobic Digestion V1.4," National Renewable Energy Laboratory (NREL). [Online]. Available: https://financere.nrel.gov/finance/content/crest-cost-energy-models. [Accessed: 28.08.2017]. 
[33] L. Olatomiwa, S. Mekhilef, M. Ismail, and M. Moghavvemi, "Energy management strategies in hybrid renewable energy systems: A review," Renewable and Sustainable Energy Reviews, vol. 62, pp. 821-835, 2016.

[34] L. Meng, E. R. Sanseverino, A. Luna, T. Dragicevic, J. C. Vasquez, and J. M. Guerrero, "Microgrid supervisory controllers and energy management systems: A literature review," Renewable and Sustainable Energy Reviews, vol. 60, pp. 1263-1273, 2016.

[35] C.-S. Karavas, G. Kyriakarakos, K. G. Arvanitis, and G. Papadakis, "A multi-agent decentralized energy management system based on distributed intelligence for the design and control of autonomous polygeneration microgrids," Energy Conversion and Management, vol. 103, pp. 166-179, 2015.

[36] A. Maitra, A. Pratt, T. Hubert, D. Wang, K. Prabakar, R. Handa, et al., "Microgrid controllers: Expanding their role and evaluating their performance," IEEE Power and Energy Magazine, vol. 15, pp. 41-49, 2017.

[37] T. A. Nguyen and M. Crow, "Stochastic optimization of renewable-based microgrid operation incorporating battery operating cost," IEEE Transactions on Power Systems, vol. 31, pp. 2289-2296, 2016.

[38] J. C. Beddoes, K. S. Bracmort, R. T. Burns, and W. F. Lazarus, "An analysis of energy production costs from anaerobic digestion systems on US livestock production facilities," USDA NRCS Technical Note, 2007.

[39] J. Wang, P. Liu, J. Hicks-Garner, E. Sherman, S. Soukiazian, M. Verbrugge, et al., "Cycle-life model for graphite-LiFePO 4 cells," Journal of Power Sources, vol. 196, pp. 3942-3948, 2011.

[40] S. Watanabe, M. Kinoshita, T. Hosokawa, K. Morigaki, and K. Nakura, "Capacity fading of LiAlyNi 1- x-y Co x O 2 cathode for lithium-ion batteries during accelerated calendar and cycle life tests (effect of depth of discharge in charge-discharge cycling on the suppression of the micro-crack generation of LiAlyNi 1- $x^{-}$y Co x O 2 particle)," Journal of Power Sources, vol. 260, pp. 50-56, 2014.

[41] T. P. Hanusa, The lightest metals: Science and technology from Lithium to Calcium: John Wiley \& Sons, 2015.

[42] V. Jülch, "Comparison of electricity storage options using levelized cost of storage (LCOS) method," Applied Energy, vol. 183, pp. 1594-1606, 2016.

[43] "Lazard's Levelized Cost of Storage Analysis V1.0," Lazard, 2015. [Online]. Available: https://www.lazard.com/media/2391/lazards-levelized-cost-of-storage-analysis-10.pdf. [Accessed: 28.08.2017].

[44] N. Nitta, F. Wu, J. T. Lee, and G. Yushin, "Li-ion battery materials: present and future," Materials today, vol. 18, pp. 252-264, 2015.

[45] B. Nykvist and M. Nilsson, "Rapidly falling costs of battery packs for electric vehicles," Nature Climate Change, vol. 5, pp. 329-332, 2015.

[46] S. Sun, T. Guan, B. Shen, K. Leng, Y. Gao, X. Cheng, et al., "Changes of degradation mechanisms of LiFePO4/Graphite batteries cycled at different ambient Temperatures," Electrochimica Acta, vol. 237, pp. 248-258, 2017. 